\title{
Modeling PPRV pathogenesis in mice to assess the contribution of innate cells and anti-viral $T$ cells
}

Yashu Sharma ${ }^{1,5}$, Roman Sarkar ${ }^{1,5}$, Ayush Jain ${ }^{1}$, Sudhakar Singh ${ }^{1}$, Chander Shekhar ${ }^{1}$, ChandraSekar Shanmugam ${ }^{2}$, Muthuchelvan Dhanavelu², Prabhakar Tembure ${ }^{3}$, Rajeev Kaul $^{4^{*}}$, Sharvan Sehrawat ${ }^{1^{*}}$

${ }^{1}$ Department of Biological Sciences

Indian Institute of Science Education and Research Mohali

Sector 81, SAS Nagar Knowledge City

PO Manauli Mohali 140306 Punjab India

${ }^{2}$ Division of Virology

Mukteshwar UK

${ }^{3}$ Department of Veterinary Microbiology

Nagpur Veterinary College

Nagpur MH 440001

${ }^{4}$ Department of Microbiology

${ }^{5}$ These authors contributed equally to the work. The author order is decided by the 28 seniority of authors.

Running title: Susceptibility and pathogenesis of PPRV in mice.

*Address for correspondence

36 sharvan@iisermohali.ac.in or rkaul@south.du.ac.in

\section{Conflict of financial interest:}

39 The authors declare no conflict of financial interest.

40 The study was supported by extramural grant from National Agriculture Science Fund 41 (NASF/ABA-6021/2017-18). 


\section{Abstract}

43 We demonstrate a rapid induction of type I IFN response in PPRV stimulated cells 44 and the susceptibility of mice, genetically ablated of interferon response, to PPRV 45 infection. Following PPRV infection, IFNR KO mice gradually reduced their body 46 weights and succumbed to the infection within 10 days. While the infecting inoculum 47 size did not alter the outcome of infection, the nature of the induced disease was 48 qualitatively different. Immunopathological lesions were characterized by the 49 expansion and infiltration of innate immune cells distinctly evident at the lower 50 infecting dose of PPRV infection. The replicating virus particles as well as the viral 51 antigens were abundant in most of the critical organs of PPRV infected IFNR KO 52 mice. Neutrophils and macrophages transported the replicating virus to central 53 nervous system and contributed to pathology while the NK cells and T cells were 54 protective against the virus. Using an array of fluorescently labeled $\mathrm{H}-2 \mathrm{~K}^{\mathrm{b}}$ tetramers 55 PPRV specific $\mathrm{CD}^{+} \mathrm{T}$ cells responses were identified and measured in the infected 56 as well as the peptide immunized mice. Our study therefore established and 57 employed a laboratory animal model for investigating PPRV pathogenesis and the 58 contribution of virus specific $\mathrm{CD}^{+} \mathrm{T}$ cells during the virus infection to pave the way 59 for elucidating protective or pathological roles of immune cells during PPRV 60 infection. 


\section{Importance}

63 We developed a laboratory animal model for investigating the pathogenesis and

64 immunity induced by PPRV. IFNR KO animals succumbed to the infection

65 irrespective of the dose and the route of infection. Neutrophils and macrophages

66 served as the Trojan horse and helped transport the virus to CNS to cause encephalitis

67 while the NK cells and $\mathrm{CD}^{+} \mathrm{T}$ cells provided the protection against PPRV infection.

68 We additionally identified class I restricted immunogenic epitopes of PPRV in

69 C57BL/6 mice. Our study therefore paves the way for an optimal utilization of this

70 model to unravel PPRV pathogenesis and assessing the host correlates of protection. 


\section{Introduction}

72 Peste des petits ruminants virus (PPRV) causes high mortality in herds of

73 small ruminants such as sheep and goats and is responsible for major economic

74 losses to livestock sector in developing countries (1-4). PPRV is a negative sense,

75 single stranded enveloped virus of paramyxoviridae family that also include other

76 members that cause debilitating diseases in animals as well as humans. These

77 include Rinderpest virus (RPV) and Canine distemper virus (CDV) of animals and

78 measles virus $(\mathrm{MeV})$ and mumps virus $(\mathrm{MuV})$ of humans $(5,6)$. PPRV genomes

79 encode for six structural proteins i.e., nucleocapsid $(\mathrm{N})$, phosphoprotein $(\mathrm{P})$, matrix

$80(\mathrm{M})$, fusion $(\mathrm{F})$, hemagglutinin $(\mathrm{H})$ and polymerase $(\mathrm{L})$ and two nonstructural proteins,

$81 \mathrm{C}$ and $\mathrm{V}$ (5). The protective and pathological mechanisms activated by the virus as

82 well as the roles of immune cells in its pathogenesis have not yet been adequately

83 elucidated that is primarily attributed to the unavailability of a laboratory animal

84 model. We therefore investigated PPRV pathogenesis in a more accessible vertebrate

85 laboratory animal model to better understand immunity and immunopathology

86 induced by PPRV.

87 Currently, a live attenuated prophylactic vaccine against PPRV is used in small

88 ruminants. While the vaccine induces a lasting immunity, a transient

89 immunosuppression is usually evident in vaccinated animals that could enhance their

90 susceptibility to heterologous infections $(3,5)$. Therefore, it is imperative to study the

91 contribution of cellular and molecular mediators induced by the virus in infected

92 animals to better understand its pathogenesis and help devise improved vaccination

93 strategies should a need arise. This is even more relevant for the contemporary animal

94 health care system as the extensive efforts are made to eradicate PPRV globally. That

95 an intensive vaccination program could help eradicate PPRV is bolstered by the 
96 success achieved in eradicating a related RPV. Therefore, an accessible laboratory

97 animal model for elucidating PPRV pathogenesis is likely to improve our

98 understanding of the induced molecular and cellular mediators. Similarly such a model

99 would shed light on the host correlates of protection.

100 We demonstrate a rapid induction of type I IFNs ( $\alpha$ and $\beta$ ) as well as IFN- $\gamma$

101 response in PPRV-stimulated immune cells but the kinetics of response varied

102 depending on the cell types and the dose of the stimulating virus. Mice genetically

103 deficient for IFN response (AG129) succumbed to the infection within ten days

104 irrespective of the dose of inoculum or the route of PPRV infection. The inoculum

105 size altered the pathology qualitatively. A lower infecting dose of the virus induced

106 predominantly an immunopathological response in mice infected with PPRV via

107 intranasal route. The replicating PPRV as well as its antigens were detected in most

108 of the analyzed organs. Innate immune cells such as neutrophils and macrophages

109 likely transported the replicating virus to CNS and elsewhere. A reconstitution of

110 IFNR KO mice with wild type $\mathrm{CD}^{+} \mathrm{T}$ cells conferred a survival advantage during

111 infection, a suggestion for their critical role in the PPRV control. We also identified

112 immunogenic class I $\left(\mathrm{H}-2 \mathrm{~K}^{\mathrm{b}}\right)$ restricted epitopes of PPRV in mice using epitope

113 prediction tools and demonstrated their immunogenicity ex vivo and in vivo.

114 Therefore, our study established a laboratory animal model that could be valuable for

115 understanding the immunological and virological parameters of morbilivirus induced

116 diseases. 


\section{Materials and Methods}

\section{Virus and cells}

PPRV vaccine strain Sungri/96 was used for all the ex vivo and in vivo

121 experiments. The virus was cultured, harvested and titrated using Vero cells and

122 stored at $-80^{\circ} \mathrm{C}$ till further use as described earlier $(4,7)$. The infecting dose of the

123 virus was calculated as $\mathrm{TCID}_{50}$ values by a previously described method (8).

124 RAW264.7 cells were cultured in complete RPMI medium supplemented with $10 \%$

125 FBS and penicillin-streptomycin in a humidified $\mathrm{CO}_{2}$ incubator.

\section{Antibodies and other biological reagents}

Antibodies used in this study were purchased from BD Biosciences, Tonbo

128 biosciences, BioLegend, and eBiosciences. The antibodies used were against CD4

129 (clone GK1.5), purified CD16/32 (Clone 2.4G2), CD11b (clone M1/70), Gr1 (clone

130 RB6-8C5), F4/80 (clone T45-2342), CD8 (clone 53-6.7), H2K ${ }^{\mathrm{b}}$ (clone AF6 88.5),

131 mouse IgG, CD45.1 (clone A20), CD45.2 (clone 1O4), CXCR3 (clone 173), CD44

132 (clone IM7), CD62L (clone MEL 14) and CD45 (Clone 30-F11). All the antibodies

133 were diluted in FACS buffer. Other reagents such as DMEM, RPMI 1640, and

134 penicillin-streptomycin antibiotic were purchased from Lonza. Trypsin, SYBR Green

135 and propidium iodide were obtained from Life Technologies. H\&E was from HiPrep,

136 M-CSF was from Peprotech and OCT compound was obtained from Fisher

137 HealthCare. FBS, p-nitrophenol phosphate and Freund's complete and incomplete

138 adjuvant were procured from Sigma-Aldrich.

\section{Generation of bone marrow derived macrophages (BMDMs)}

140 Long bones were collected from sacrificed C57BL/6 mice and sterilized in

$14170 \%$ alcohol. Bone marrows were removed to prepare single cell suspension as

142 described earlier (9). RBCs present in the bone marrow cells were lysed and the bone 
143 marrow cells were cultured in 48 well plates $\left(1 \times 10^{6}\right.$ cells/well $)$ in the presence of

144 10ng/ml M-CSF for 7 days. Media was changed after every two days. The cells were

145 cultured in 10\% RPMI (Gibco $\square$ BRL, Rockville, MD, USA) supplemented penicillin

$146(100 \mathrm{U} / \mathrm{mL})$ and streptomycin $(100 \mu \mathrm{g} / \mathrm{mL})$. After 7 days, cells were collected, washed

147 and stained for F4/80 positive and CD11c negative population for phenotypic

148 characterization and for performing further experiments.

149 Measuring type I and II IFN response in PPRV pulsed macrophage cell line and

150 primary BMDM cells

151 RAW macrophages and BMDMs were pulsed with PPRV at multiplicity of

152 infection (MOI) of 1 and 10 to measure the kinetics of type I IFNs ( $\alpha$ and $\beta$ ) and

153 IFN- $\gamma$ response by qualitative real time polymerase chain reaction (RT-PCR). Murine

154 macrophages and RAW cells pulsed with replicating PPRV or the inactivated virus

155 and samples were collected at $15 \mathrm{~min}, 30 \mathrm{~min}, 1 \mathrm{hr}$ and $6 \mathrm{hr}$. The cells were processed

156 for isolating mRNA at different time points. The mRNA was converted into cDNA

157 using a first strand synthesis kit (Verso cDNA synthesis kit, Thermo Fisher

158 Scientific). The expression of hypoxanthine phosphoribosyltransferase 1 (HPRT 1)

159 gene served as an internal control. The relative expression for each gene was

160 calculated by using $\Delta(\Delta \mathrm{Ct})$ method.

161 Infection of mice with PPRV

162 All the experiments involving animal experiments were performed strictly in 163 accordance with the protocol approved by the Institutional Animal Ethics

164 Committee, IISER Mohali, constituted under the aegis of committee for the purpose

165 of control and supervision of experiments on animals (CPCSEA). IFNR KO

166 (AG129) and congenic C57BL/6 mice (CD45.1 and CD45.2) were used for in vivo

167 experiments. Animals were infected using intraperitoneal (i.p) or intranasal (i.n) 
168 routes with the indicated doses of PPRV. Different physiological parameters such as

169 body weight, body temperature, behavior and the mortality pattern were measured in

170 different groups of animals. For most of the experiments, the animals were sacrificed

171 at the termination of experiments when the body weight for any of the groups

172 dropped by more than $20 \%$. Different lymphoid and non-lymphoid organs were

173 collected to detect the replicating virus, viral antigens, and performing the cellular

174 analysis in lymphoid organs such as spleen, mediastinal LNs as well as non-

175 lymphoid organs such as bronchoalveolar lavage (BAL), lungs and brain tissues.

176 Before collecting organs from different groups of mice, a heart perfusion with $20 \mathrm{ml}$

177 of PBS was performed to remove any contaminating cells of blood from the collected

178 organs.

179 Reconstitution of IFNR KO mice with $T$ cells to measure their anti-PPRV 180 functions

181 In order to measure the protective ability of immune cells, the graded doses 182 of MACS purified CD4 ${ }^{+}$and $\mathrm{CD}^{+} \mathrm{T}^{-}$cells from C57BL/6 WT mice were adoptively 183 transferred in sex matched IFNR KO animals. The recipient animals were 184 subsequently infected with PPRV. Mice not transferred with any cells served as the 185 control. Recipient animals were observed for their body wight and survival. At the 186 termination of experiments, lymphoid organs of animals were collected for cellular 187 analysis.

188 Cell purification and adoptive transfer

189 The different subsets of $\mathrm{T}$ cells and innate immune cells such as 190 macrophages, neutrophils, dendritic cells were isolated from C57BL/6 mice either by 191 magnetic cell sorting kits or by FACS sorting. The sorted cells were collected at low 192 temperature in the complete RPMI. The cells were pulsed with PPRV for one hour. 
193 After extensive washings, the cells were counted and the indicated numbers of cells

194 were transferred i.v in IFNR KO mice.

\section{Bioinformatic analysis to predict immunogenic peptides of PPRV}

Amino acid sequences of PPRV structural proteins were retrieved from

197 National Centre for Biotechnology Information (NCBI) database in FASTA Formats.

198 The immunogenic peptides for one of the class I MHC molecules of C57BL/6 mice

$199\left(\mathrm{H}-2 \mathrm{~K}^{\mathrm{b}}\right)$, were predicted using immune epitope data and analysis resource (IEDB).

200 The software uses artificial network (ANN) and stabilized matrix method (SMM).

201 The percentile rank of $<2$ and $\mathrm{IC}_{50}$ values were selected for the prediction. A low

202 percentile rank and the lower $\mathrm{IC}_{50}$ values of $<50 \mathrm{nM}$ indicated high affinity binders.

203 The peptides with $\mathrm{IC}_{50}$ values between 50 and $<500 \mathrm{nM}$ were considered as

204 intermediate affinity binders while with values $>500 \mathrm{nM}$ were considered as the low

205 affinity binders (10). Additional parameter for selecting peptides was their

206 immunogenicity scores $(11,12)$. Additionally a percentile rank for the predicted

207 peptides was generated by comparing $\mathrm{IC}_{50}$ values of predicted epitopes against a set

208 of random peptides using SWISSPROT database. The selected peptides were

209 commercially synthesized and obtained from GL Biochem. The purity of the synthetic

210 peptides was greater than $90 \%$.

211 Molecular Docking analysis

212 For predicting the binding affinities of different peptides for class I MHC 213 molecules (H-2 $\mathrm{K}^{\mathrm{b}}$ and Caprine Leucocyte antigen, CLA1), molecular docking 214 analyses were performed using HPEPDOCK-web server. Default parameters were 215 used for all the docking experiments as described elsewhere (13). HPEPDOCK 216 server uses a hierarchical algorithm, MODPEP program for a blind protein-peptide 217 docking and generates an ensemble of peptide conformation by considering 
218 flexibility conformation in the respective peptide and the PDB File 1S7Q for the

219 homology modeling with $\mathrm{H}-2 \mathrm{~K}^{\mathrm{b}}$ protein. To test the efficiency of docking algorithm,

220 a known immunogenic 9-mer peptide derived from Sendai E virus (SEV)

221 nucleoprotein (FAPGNYPAL) was used for docking with $\mathrm{H}-2 \mathrm{~K}^{\mathrm{b}}$. Since the outcome

222 of docking could be dictated by a potentially problematic algorithm that

223 overemphasize the numbers of interactions rather than the conformation, we referred

224 to the solved crystal structure of a nonameric peptide (SEV-9) with $\mathrm{H}-2 \mathrm{~K}^{\mathrm{b}}$ to better

225 predict the results from docking analyses. We then compared the energy parameters

226 of the best-selected structures among different PPRV peptides docked with $\mathrm{H}-2 \mathrm{~K}^{\mathrm{b}}$.

227 To further refine and define the interacting residues both quantitatively and

228 qualitatively, we used molecular modeling program UCSF Chimera for binding

229 analysis (14). As the goal of such experiments was to explore the translational value

230 of such peptides in small ruminants, we superimposed $\mathrm{H}-2 \mathrm{~K}^{\mathrm{b}}$ with goat class I MHC

231 (CLA-1) molecule at 1.5A RMSD (root mean square distance) using the tool,

232 Matchmaker, available in the UCSF Chimera. Similarly docking studies were done

233 for CLA-I with different PPRV peptides and the representative docked structures

234 were generated using UCSF Chimera. A comparative analysis between docking

235 scores of $\mathrm{H}-2 \mathrm{~K}^{\mathrm{b}}$ and CLA-I for the similar peptides was also performed.

\section{Class I MHC stabilization assays}

237 The stabilization of class I MHC by each peptide was measured using both

238 cellular and acellular assays. TAP deficient murine T cell lymphoma cells (RMA/s

239 cells) were used for determining the peptide induced surface stabilization of class I

240 MHC molecule by flow cytometric analysis as described earlier (15). RMA/s cells

241 were maintained in RPMI (Gibco $\square$ BRL, Rockville, MD, USA) supplemented with

$24210 \%$ fetal bovine serum (FBS), penicillin $(100 \mathrm{U} / \mathrm{mL})$ and streptomycin $(100 \mu \mathrm{g} / \mathrm{mL})$. 
$2432 \times 10^{5}$ cells were serum starved for $3 \mathrm{hrs}$ at $37^{\circ} \mathrm{C}$ and subsequently pulsed with the

244 respective peptides to induce their surface class I MHC $\left(\mathrm{H}-2 \mathrm{~K}^{\mathrm{b}}\right)$ stabilization. Graded

245 doses of peptides were added in serum free RPMI followed in which cells cells were

246 incubated at $37^{\circ} \mathrm{C}$ for $7 \mathrm{hrs}$. The cells were then washed with PBS and stained with

247 anti anti-H-2K $\mathrm{K}^{\mathrm{b}}$-FITC antibody. Live and dead cells were differentiated using

248 propidium iodide (PI) staining. The cells were analysed by FACS Accuri flow

249 cytometer (BD Biosciences, Breda, The Netherlands). The data is represented as

250 percent positive cells or the mean fluorescence intensities (MFI) for the expression of

$251 \mathrm{H}-2 \mathrm{~K}^{\mathrm{b}} . \mathrm{EC}_{50}$ value for high affinity peptides were then calculated.

252 An acellular assay was also used for determining the class I MHC 253 stabilization as described elsewhere (16). Briefly, ELISA plates were coated with 254 streptavidin overnight at $4^{\circ} \mathrm{C}$. Subsequently, $\mathrm{H}-2 \mathrm{~K}^{\mathrm{b}}$ monomers were added to the 255 plates. The monomers were generated by refolding a UV photocleavable ligand, 256 (FAPG(Anp)YPAL), $\beta 2$ microglobulin and $\mathrm{H}-2 \mathrm{~K}^{\mathrm{b}}$ heavy chain followed by their 257 biotinylation as described earlier $(15,17)$. The unbound $\mathrm{H}-2 \mathrm{~K}^{\mathrm{b}}$ monomers were 258 washed and the control and PPRV peptides were added to the identified wells in the 259 plates. The plates were then exposed to UV radiations at $365 \mathrm{nM}$ for $30 \mathrm{~min}$ to 260 achieve the displacement of UV ligand with respective peptides. The efficiency of 261 exchange was measured by probing the washed plates by adding anti- $\beta 2$ 262 microglobulin antibody. Subsequently, a mouse anti-IgG antibody enzyme conjugate 263 (1:10000) was added after washing the plates. Thereafter, substrate, (p-nitrophenol 264 phosphate $(1 \mathrm{mg} / \mathrm{ml})$ was added for its conversion into a chromogenic product. The 265 stop solution was used to block the reaction and the plates were measured for 266 absorbance at $405 \mathrm{~nm}$. Positive and negative controls were also included in the study 267 (18). 
268 PPRV infection and peptide immunization of mice for PPRV specific $\mathrm{CD8}^{+} \mathrm{T}$ 269 cell analysis

270 In order to determine the immunogenicity of predicted peptides in vivo, we 271 performed two types of experiments. Throughout the manuscript, plaque forming 272 units (PFU) and focal forming units (FFU) are used interchangeably as clear plaques 273 are not observed when PPRV in grown in Vero cells. In first set of experiments, WT 274 C57BL/6 mice were i.p. infected with a high dose of PPRV (5x10 6 PFU). After seven 275 days a second dose of PPRV was given to animals to boost responses. The analysis 276 of the expanded cells was performed three days later by measuring the frequencies 277 PPRV-peptide specific $\mathrm{CD}^{+} \mathrm{T}$ cells by tetramer staining. In second set of 278 experiments, C57BL/6 mice were immunized either with the cocktail of peptide 279 (AILTFLFLL, FMYLFLLGV, FSAGAYPLL and IGLVRDFGL) each with $2805 \mu \mathrm{g} /$ mouse in complete Freund's adjuvant subcutaneously. After two weeks, a 281 second injection of the same concentration was administered but emulsified in the 282 incomplete Freund's adjuvant. Three days later the frequencies of peptide specific $283 \mathrm{CD}^{+} \mathrm{T}$ cells were analyzed by tetramer staining of PBMCs.

284 Isolation of inflammatory cells from brain tissues and lungs

285 Inflammatory cells were isolated from the brains and lungs of IFNR KO mice 286 by using protocol as described earlier (19). Briefly, brain tissues were minced into 3$2874 \mathrm{~mm}$ pieces with a sterile scalpel or scissors under complete aseptic conditions. 288 Washing was done 4-5 times with 10mM PBS. Extra supernatant was removed from 289 tissue pieces container kept on ice. $0.25 \%$ trypsin was added to samples followed by 290 their incubation at $4^{\circ} \mathrm{C}$ for $16 \mathrm{hrs}$. Then, trypsin was discarded and incubation was 291 done at $37^{\circ} \mathrm{C}$ for $30 \mathrm{~min}$. Complete RPMI was added to prepare single cell 292 suspension. After washing with PBS, cells were used further for experiments. 
293 Flow cytometry for cellular analysis

294 Different lymphoid and non-lymphoid organs were collected from infected or

295 immunized mice. The single cell suspensions were prepared from collected organs

296 for cellular analysis. The cells were stained using indicated fluorescent labeled

297 antibodies at cold temperature for 30 minutes. Fc block was done before surface

298 staining. Stained cells were acquired by FACS Accuri or BD FACS Aria fusion. The

299 analysis of the data was performed by Flow Jo software.

\section{Fluorescent microscopy and histological analysis}

301 The organs collected from infected and control animals were stored in OCT 302 compound. Tissue sections of $6 \square \mathrm{m}$ were cut and dried. The dried sections were first 303 blocked with anti-CD16/CD32 antibodies followed by incubation with anti-PPRV H 304 and $\mathrm{N}$ monoclonal antibodies. Anti mouse FITC IgG antibodies were then used as 305 secondary antibodies. The sections were analyzed using a fluorescent microscope 306 and the images were generated by Image J software. Similarly, the tissue section 307 from brain tissues were dried and stained with Hematoxylin and Eosin Y. The 308 sections were analyzed by Leica DMi8 microscope as described earlier (20).

309 Statistical analysis

310 Statistics was applied to the data and analysed by using ANOVA, Student $\mathrm{t}$

311 test or the Gehan-Breslow-Wilcoxon test as indicated in the respective figures. Graph

312 Pad Prism v5.03 was used for such analysis. The level of significance was

313 determined as $\mathrm{P}<0.05 *, \mathrm{P}<0.01 * *, \mathrm{P}<0.001 * * *, \mathrm{P}<0.0001 * * * *$. 


\section{Results}

\section{PPRV infection induces a rapid interferon response}

318 Interferon response constitutes the first line of an anti-viral defense 319 mechanism. We therefore measured the expression of both type I $(\alpha, \beta)$ and type II $320(\gamma)$ IFN response in a murine macrophage cell line (RAW macrophages) and the

321 primary BMDMs that were stimulated with a low (1MOI) and high (10MOI) dose of

322 PPRV. A low dose of PPRV as compared to the high dose induced significantly more

323 IFNọin RAW macrophages at $1 \mathrm{hr}$ post stimulation (Fig 1A). However, a reverse

324 trend as well as an early induction was observed in BMDMs (Fig 1D). Furthermore,

325 the overall expression levels of IFN $\alpha$ were approximately 100 fold more in the 326 primary BMDMs as compared to those in RAW macrophages (Fig 1A and D).

327 Interestingly, we observed a very rapid induction of IFN $\alpha$ within $15 \mathrm{~min}$ of 328 stimulation by primary BMDMs but its expression was evident in RAW 329 macrophages only after 1 hour (Fig 1A and D). Similarly IFN $\beta$ expression was only 330 detectable at significant levels in PPRV stimulated RAW macrophages after 1hour 331 (Fig 1B). In stimulated BMDMs, the message of IFN $\beta$ was evident albeit at lower 332 levels as compared to that of IFN $\alpha$ (Fig1E). IFN $\gamma$ was induced at a low infecting 333 dose of PPRV in RAW cells but the primary BMDMs expressed it in significant 334 levels only at the high MOI of PPRV (Fig 1C and F). The heat inactivated PPRV 335 induced the production of both type I and type II IFNs but to a much lesser extent 336 and that too in the early stages of stimulation (Fig S1). These results might suggest 337 that not only the viral genome or its replication intermediates but also some of the 338 PPRV proteins could serve as the PAMPs for inducing IFN responses. 
340 stimulated cells but the overall expression was dependent on the infecting dose as

341 well as the nature of responding cells. The expression profile of type I interferon

342 (IFN $\alpha$ and IFN $\beta$ ) also indicated a dichotomy in their function with the IFN $\alpha$ being

343 induced rapidly and in high concentrations but IFN $\beta$ was produced later on. Such a

344 response pattern could diversify the IFN response in providing an antiviral state.

345 Mice genetically depleted of IFNRs are susceptible to PPRV infection

346 Having demonstrated a rapid induction of IFN response in the PPRV pulsed

347 macrophages; we tested whether or not the mice, unable to mount IFN response

348 because of genetic ablation of the signaling receptors, are susceptible to PPRV.

349 Different doses of PPRV $\left(1,10^{2,} 10^{3}\right.$ and $10^{4}$ PFU) were i.p inoculated into IFNR KO

350 mice and the disease progression was monitored (Fig 2A). We first measured the

351 survival of PPRV infected animals up to eight dpi. All the infected animals

352 succumbed to the infection albeit survival duration was dependent on the initial

353 inoculum (Fig 2B). Accordingly, animals infected with the high dose died earlier as

354 compared to those infected with the lower dose of PPRV (Fig 2B). We then

355 measured other physiological parameters and body weights in the infected animals

356 (Fig 2C). All the infected animals gradually lost their body weights, developed

357 encephalitic lesions and became hypothermic (Fig 2C and data not shown). By 7dpi,

358 all the animals succumbed to the infection irrespective of the doses of virus inoculum

359 used (Fig 2C). In similar experiments, PPRV infected WT mice remained refractory

360 to the PPRV induced disease as no clinical signs were observed even in those

361 infected with the high infecting dose $\left(5 \times 10^{6} \mathrm{PFU}\right)$ (Fig $2 \mathrm{~B}$ and $\left.\mathrm{C}, \mathrm{S} 6 \mathrm{~B}\right)$. The results,

362 therefore, underscored the critical role of IFN signaling in providing an early defense

363 against PPRV infection in mice. 
365 the presence of PPRV antigens in the brain tissue sections by fluorescent microscopy

366 using anti-PPRV $(\mathrm{H})$ monoclonal antibodies. We also measured the replicating virus

367 particles in brain tissue homogenates by performing plaque-forming assays.

368 Fluorescent microscopic images of brain tissue sections from the infected animals

369 revealed an abundance of viral antigens particularly when the animals were infected

370 with the high doses of the virus inoculum (Fig 2D). A dose dependent increase in the

371 PPRV loads was recorded in the homogenized brain tissues (Fig 2E). Accordingly,

372 the replicating virus titers were $3.6 \pm 0.3,5.0 \pm 0.4$ and $6.4 \pm 0.3 \log _{10} / \mathrm{g}$ of brain

373 tissues at the infecting dose of $1,10^{2}$ and $10^{4} \mathrm{PFU}$, respectively (Fig 2E). We also

374 collected different organs such as lungs, livers, hearts, brains and kidneys of mice

375 infected with 1 or $1.5 \times 10^{6}$ PFU of PPRV to measure the virus loads as well as to

376 detect the presence of viral antigens (Fig 2F-H). The fluorescent microscopic images

377 showed the presence of PPRV antigens in the tissue sections of liver, lung and heart

378 of infected animals given $1.5 \times 10^{6} \mathrm{PFU}$ (Fig 2F). The virus titers in liver, lung and

379 heart were $7.3 \pm 1.0,5.2 \pm 0.5$ and $4.9 \pm 0.08 \log _{10} \mathrm{PFU} / \mathrm{g}$ of tissue, respectively (Fig

380 2G). The virus load in the animals infected with a low dose of 1 PFU of PPRV were

$3814.3 \pm 0.8,5.8 \pm 0.8,6.0 \pm 0.3,6.1 \pm 0.2$ and $5.7 \pm 0.8 \mathrm{PFU} \log _{10} / \mathrm{g}$ of tissue in heart,

382 lungs, liver, spleen and kidneys, respectively (Fig $2 \mathrm{H}$ ). Our results therefore

383 suggested an active replication of PPRV in different organs of mice deficient in IFNs

384 signaling.

385 IFNR KO mice were susceptible to PPRV infection even at a very low

386 inoculum size (1PFU); we therefore investigated whether or not the infecting dose

387 qualitatively influenced the disease. The brain tissue sections from animals infected

388 with varying doses of PPRV were stained with H\&E and the single cell suspensions 
389 from brain tissues were analyzed by flow cytometry (Fig 2I). A high dose of PPRV

390 induced swelling of meninges in the infected brain tissues (Fig 2I, right panel).

391 Interestingly, the stained sections of brain tissues from animals infected with low

392 dose of PPRV (1PFU) showed greater leukocytic infiltration as compared to those

393 infected with the high dose (Fig 2I, left panel). We also analyzed the phenotype of

394 leukocytes from the single cell suspension of brain tissues by flow cytometry. The

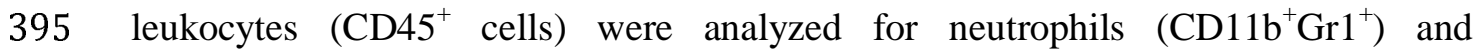

396 macrophages $\left(\mathrm{CD} 11 \mathrm{~b}^{+} \mathrm{F} 4 / 80^{+}\right)$. Significantly higher frequencies of neutrophils were

397 present in the brain samples of PPRV infected mice as compared to the uninfected

398 controls (Fig 2J and K). The frequencies of macrophages also increased but the

399 results were not statistically different in control and infected mice (Fig 2L and M).

400 The increase in the frequencies of innate immune cells further supported the results

401 that the infected mice developed encephalitic lesions.

402 Many members of genus morbillivirus are neurovirulent and the PPRV

403 induced neurovirulence in naturally infected goat neonates was shown recently (21-

404 23). Therefore, the infectivity of IFNR KO mice by PPRV, their observed

405 neurovirulence as well as immune cells infiltration in infected tissues could suggest

406 that these mice could represent a better accessible model for deciphering molecular

407 and cellular mechanisms occurring during PPRV pathogenesis.

408 Innate immune cells are permissive to PPRV infectivity

409 We established the infectivity of IFNR KO mice and showed the 410 responsiveness of adaptive and innate immune cells. We then measured the immune 411 response in spleens of PPRV infected IFNR KO mice (Fig 3). The frequencies of 412 innate immune cells such as neutrophils $\left(\mathrm{CD} 11 \mathrm{~b}^{+} \mathrm{Gr} 1^{+}\right)$increased by upto 10 fold in 413 PPRV infected mice as compared to controls (Fig 3A and B). Other innate immune 
414 cells such as macrophages $\left(\mathrm{CD} 11 \mathrm{~b}^{+} \mathrm{F} 4 / 80^{+}\right)$and $\mathrm{DCs}\left(\mathrm{CD} 11 \mathrm{~b}^{+} \mathrm{CD} 11 \mathrm{c}^{+}\right)$also showed

415 a significant increase in PPRV infected mice in comparison to control but to a lesser

416 extent as compared to those of neutrophils (Fig 3F, G, K and L). A rapid induction of

417 innate immune cells after PPRV infection and the expression of encephalitic lesions

418 in infected IFNR KO mice even at a low dose of the virus led us to explore the

419 possibility of virus transport to CNS by such cells. We, therefore, measured the

420 infectivity of innate immune cells by PPRV using intracellular staining for the viral

421 proteins. Neutrophils $\left(\mathrm{Gr}^{+}\right)$, macrophages $\left(\mathrm{F} 4 / 80^{+}\right)$, and $\mathrm{DCs}\left(\mathrm{CD} 11 \mathrm{c}^{+}\right)$from control

422 and the infected animals were measured for the presence of PPRV heamaglutinin $(\mathrm{H})$

423 and nucleocapsid (N) proteins using monoclonal antibodies (24). In morbilliviruses,

$424 \mathrm{~N}$ proteins are highly conserved and represent a major component of

425 ribonucleoprotein complex while the $\mathrm{H}$ proteins help virus attach to the target cells.

426 A significantly higher frequency of neutrophils isolated from PPRV infected mice

427 showed the presence of $\mathrm{H}$ and $\mathrm{N}$ viral proteins (Fig 3C-E). Although PPRV proteins

428 were also present in the macrophages and DCs of infected animals but the results

429 were not statistically significant (Fig 3H-J and M-O). Therefore, neutrophils and

430 perhaps other innate immune cells by virtue of their PPRV infectivity might

431 contribute to the virus transport to different tissues.

432 Innate immune cells transport PPRV to central nervous system

433 We investigated whether or not innate immune cells help transport PPRV to

434 CNS. PPRV infected innate immune cells were adoptively transferred in congenic

435 mice followed by monitoring the disease progression in recipients (Fig 4A).

436 Neutrophils, macrophages and dendritic cells were FACS sorted from WT congenic

437 mice $\left(\mathrm{CD} 45.1^{+}\right)$. The sorted cells were infected with PPRV and after extensive

438 washings; these cells were transferred into sex matched IFNR KO mice (CD45.2 $\left.{ }^{+}\right)$ 
439 (Fig 4A). We recovered enhanced frequencies of neutrophils $\left(\mathrm{CD} 45.1^{+} \mathrm{CD} 11 \mathrm{~b}^{+} \mathrm{Gr} 1^{+}\right.$, $440 \sim 4 \%)$ and macrophages $\left(\mathrm{CD} 45.1^{+} \mathrm{CD} 11 \mathrm{~b}^{+} \mathrm{F} 4 / 80^{+}, \sim 2 \%\right)$ from brain tissues of

441 recipients (Fig 4B and C). Moreover, the transferred PPRV-pulsed cells resulted in a 442 patent infection in recipients with the progression of disease being similar to that 443 observed in PPRV only injected animals (Fig 4D). This data suggested that infected 444 innate immune cells particularly the neutrophils and macrophages could support virus 445 replication and transport PPRV to different organs. We did not recover significantly 446 higher frequencies of donor DCs $\left(\mathrm{CD} 45.1^{+} \mathrm{CD} 11 \mathrm{~b}^{+} \mathrm{CD} 11 \mathrm{c}^{+}\right)$in the brain tissues of 447 recipient mice but the disease severity was comparable in all the recipients (Fig 4B448 D). Several factors could explain these results such as the inability of transferred DCs 449 to directly home to brain tissues or their inefficient proliferation. Nonetheless, such 450 cells might have transferred the virus to other inflammatory cells, which then could 451 have transported it to brain tissues and elsewhere. The observed increased leukocytic 452 infiltration in the brain tissues supported this notion (data not shown). Further analysis 453 of different innate immune cells pulsed with PPRV demonstrated their infectivity as 454 PPRV antigens could be detected in such cells by flow cytometry (Fig 4E and F).

455 These results indicated that the virus could either be internalized by innate immune 456 cells or be associated to surfaces and such cells could transport PPRV to distant sites 457 such as the CNS.

458 PPRV induces lung pathologies in IFNR KO animals infected with intranasal 459 route

PPRV causes respiratory disease in infected small ruminants and the infection 461 spreads among animals in the herd due to their closer association, we therefore 462 investigated its pathogenesis in mice infected via intranasal route. IFNR KO animals 463 were infected with varying doses of PPRV and were analyzed for their survival, body 
464 weights and other physiological parameters (Fig 5). The survival analysis of animals

465 showed a significant effect of inoculum sizes but all infected animals eventual

466 outcome in all the animals remained same as was observed in the i.p. infected mice

467 (Fig S2). Thus, animals infected with the lower dose $\left(10^{2} \mathrm{PFU}\right)$ succumbed to the

468 infection later and those infected with the higher doses $\left(10^{6} \mathrm{PFU}\right)$ died within 6 days.

469 For performing the cellular analysis at the tissue sites and lymphoid organs of

470 animals, additional groups of infected animals were sacrificed when approximately

$47120 \%$ of their body weights were lost (Fig 5A, S3-6). WT animals were infected with

472 a high dose $\left(10^{6} \mathrm{PFU} / \mathrm{mouse}\right)$ as all i.p infected animals with the higher inoculum

473 size survived (Fig 2B-C, data not shown). Infected WT animals reduced their body

474 weights transiently followed by their rapid recovery until the termination of the

475 experiments while the infected IFNR KO animals gradually reduced their body

476 weights at both the doses $\left(10^{4}\right.$ PFU and $10^{6}$ PFU) of PPRV (Fig 5B). The animals

477 were terminally anaesthetized at 6dpi for performing cellular analysis in collected

478 BALs, lungs, brain and lymphoid organs. Approximately two fold higher infiltration

479 level of leukocytes was observed in the BALs of WT animals as compared to the

480 IFNR KO animals suggesting for the immune reactivity against PPRV (Fig 5C). We

481 observed an enhanced infiltration of leukocytes in the BALs ( 42\% vs 30\%) as well

482 as lung tissues (27\% vs $19 \%$ ) of IFNR KO animals infected with the low (10 $0^{2}$ PFU)

483 and high $\left(10^{4}\right.$ PFU) dose of PPRV (Fig 5C and D). That the infiltrating leukocytes

484 could be involved in protection against the virus was indicated by their inverse ratios

485 observed in the lung tissues of two groups of PPRV infected animals (Fig 5C and D).

486 This could suggest that an efficient viral control could be achieved before a patent

487 lung infection is established and leukocytes are recruited. A minimal infiltration of

488 leukocytes was evident in the brain tissues of IFNR KO and WT animals infected via 
489 intranasal route and the observed frequencies were similar in both the groups of mice

490 (Fig 5E). We then phenotypically characterized different immune cells among the

491 leukocyte populations in different organs. The relative abundance of macrophages

$492\left(\mathrm{CD} 11 \mathrm{~b}^{+} \mathrm{F} 4 / 80^{+}\right)$, neutrophils $\left(\mathrm{CD} 11 \mathrm{~b}^{+} \mathrm{Gr}^{+}\right)$, NK cells $\left(\mathrm{NK} 1.1^{+}\right.$cells $)$, helper $\left(\mathrm{CD} 4^{+}\right)$

493 and cytotoxic $\left(\mathrm{CD}^{+}\right) \mathrm{T}$ cells was measured in the non-lymphoid as well as lymphoid

494 organs of infected WT and IFNR KO mice (Fig 5F-Z). Upto a five fold reduction in

495 the frequencies of macrophages and neutrophils were observed in the BALs, lung

496 tissues, brain, mediastinal LNs and spleens of infected WT animals as compared to

497 those in IFNR KO mice (Fig 5G, H, K, L, P, Q, R, W and X). The frequencies of NK

498 cells were similar in BALs but decreased in the lung and spleen of the PPRV infected

499 WT animals as compared to those in IFNR KO mice (Fig 5I, M and Y). The

500 increased frequencies of both $\mathrm{CD}^{+}$and $\mathrm{CD}^{+} \mathrm{T}$ cells in BALs and lung tissues of

501 PPRV infected WT mice in comparison to those of the IFNR KO mice were

502 observed (Fig 5J and N). BALs and mediastinal LNs of infected IFNR KO animals

503 injected with different doses strikingly had more frequencies of neutrophils at a

504 lower dose as compared to those at high dose (Fig 5H and R). Such a trend was not

505 observed in lung tissues, brain and spleen samples of the infected animals (Fig 5L, P

506 and X). The inverse correlation with PPRV inoculum size and the recruitment of

507 macrophages was not observed in lungs, brain and spleens of IFNR KO animals

508 infected (Fig 5G, K O and W). Enhanced frequencies of NK cells but a reduction in

509 the frequencies of neutrophils and macrophages were observed for both BAL and

510 lung tissues of WT mice (Fig 5G - I and K-M). Similarly, the frequencies of both

$511 \mathrm{CD}^{+}$and $\mathrm{CD}^{+} \mathrm{T}$ cells increased in the spleens, BALs and lung tissues of PPRV

512 infected WT mice that efficiently controlled PPRV infection (Fig 5F, J and N). These

513 results suggested for the anti-PPRV activity of NK cells and T cells. 
514 We further explored whether or not PPRV infection induces the activation of

$515 \mathrm{~T}$ cells. A significant proportion of $\mathrm{CD}^{+} \mathrm{T}$ cells displayed an activation profile

$516\left(\mathrm{CD}_{2} \mathrm{~L}^{\text {lo }} \mathrm{CXCR} 3^{+}\right)$in WT animals but the frequencies of such cells were up to three

517 fold higher in the IFNR KO animals (Fig 5S and T, S5). However, the frequencies of 518 activated $\mathrm{CD}^{2} 2 \mathrm{~L}^{10} \mathrm{CXCR} 3^{+} \mathrm{CD}^{+} \mathrm{T}$ cells was $\sim 2$ fold lower in WT animals as 519 compared to those in IFN RKO mice (Fig 5U and V, S5). Innate immune cells such 520 as the NK cells in WT animals could help achieve an efficient viral control but such 521 mechanisms might require the activity of IFNs as abundant replicating viral particles 522 were present in the IFNR KO animals. Furthermore, the antigen presenting cells 523 stimulated both $\mathrm{CD}^{+}$and $\mathrm{CD}^{+} \mathrm{T}$ cells but such cells were compromised in their 524 function owing to their lack of type I IFN responsiveness.

525 Taken together, the analysis of cellular infiltration suggested for the role of 526 neutrophils in promoting PPRV pathogenesis while NK cells and T cells playing 527 protective roles.

\section{IFN responsive $\mathrm{CD8}^{+}$T cells delay mortality in PPRV infected IFNR KO mice}

529 We established the susceptibility of IFNR KO mice to PPRV, the potential 530 spread of PPRV by infected innate immune cells and expansion of innate immune 531 cells as well as T cells in PPRV infected WT mice that controlled the virus well (Fig 532 S6B). We then explored whether WT T cells could either protect infected IFNR KO 533 animals or reduce the severity of PPRV infection. FACS sorted CD4 ${ }^{+}$and $\mathrm{CD} 8^{+} \mathrm{T}$ 534 cells from WT mice were transferred into IFNR KO animals. Such cells were allowed 535 to expand for 40 days in recipients, which were then infected with PPRV (Fig S7A). 536 In comparison to infected controls that gradually lost their body weight, $\mathrm{CD}^{+} \mathrm{T}$ cell 537 recipients showed a significantly reduced body weights until their termination at 6dpi 538 (Fig S7B). WT CD4 ${ }^{+} \mathrm{T}$ cell recipient mice and those received bone marrow cells did 
539 not shown alteration in the rates or the kinetics of body weight loss (Fig S7B, data not 540 shown). The activation status of $\mathrm{CD}^{+}$and $\mathrm{CD}^{+} \mathrm{T}$ cells of control and $\mathrm{T}$ cell recipient

541 mice revealed more frequencies of $\mathrm{CD}^{+}$and $\mathrm{CD} 8^{+} \mathrm{T}$ cells expressing high levels of 542 CD44 when WT CD8 ${ }^{+}$T cells were transferred (Fig S7C-F, data not shown). These 543 results suggest anti-viral activity of $\mathrm{WT} \mathrm{CD}^{+} \mathrm{T}$ cells.

544 We then measured whether or not previously PPRV-primed WT CD8 ${ }^{+}$T cells 545 confer protection to the PPRV infected IFNR KO mice. $5 \times 10^{6}$ of FACS sorted WT $546 \mathrm{CD}^{+} \mathrm{T}$ cells from naïve or the mice previously infected with PPRV were transferred 547 before infecting IFNR KO mice with PPRV (Fig 6A). The survival analysis showed a 548 significant advantage conferred to the infected IFNR KO mice by transferred naïve or 549 primed $\mathrm{CD}^{+} \mathrm{T}$ cells in delaying mortality (Fig 6B). Such effects occurred in a dose 550 dependent manner with animals receiving five fold lower $\mathrm{CD}^{+} \mathrm{T}$ cells succumbed to 551 the infection early (Fig S7 and data not shown). Separate groups of PPRV infected $552 \mathrm{CD}^{+} \mathrm{T}$ cell recipients were measured for a change in their body weights and cellular 553 analysis on 7dpi (Fig S8 and S9). $\mathrm{CD}^{+} \mathrm{T}$ cell recipients showed significantly reduced 554 body weights by 6dpi (Fig 6C). Cellular analysis showed that approximately $50 \%$ of $555 \mathrm{CD} 45^{+}$cells were present in the BAL of PPRV infected animals and the frequencies 556 decreased to $30 \%$ in $\mathrm{CD}^{+} \mathrm{T}$ cells recipients (Fig 6D). Similarly in the lung tissues of 557 infected animals the frequencies of $\mathrm{CD} 45^{+}$cells reduced from $25 \%$ to $15 \%$ in $\mathrm{CD}^{+} \mathrm{T}$ 558 cells recipients (Fig 6E). However, such effects were prominently observed in the 559 group receiving $\mathrm{CD}^{+} \mathrm{T}$ cells from previously PPRV-infected animals. Neutrophils 560 levels increased in the BALs of $\mathrm{CD}^{+} \mathrm{T}$ cell recipients IFNR KO mice by $\sim 1.5$ fold 561 but the macrophages and NK cells decreased by 10\% (Fig 6F(a)-F(c)). In the lungs 562 tissues, no significant differences in the cellular infiltrations were observed but for an 563 increase in macrophages in $\mathrm{CD}^{+} \mathrm{T}$ cell recipients (Fig 6G). The cellular analysis in 
564 the MLN and spleen samples of infected animals revealed a reduction in the

565 frequencies of innate immune cells such as neutrophils and macrophages but more

$566 \mathrm{CD}^{+}$and $\mathrm{CD} 8^{+} \mathrm{T}$ cells were observed in $\mathrm{WT} \mathrm{CD}^{+} \mathrm{T}$ cell recipient mice (Fig $6 \mathrm{~J}$ and

$567 \mathrm{H})$. Phenotypic characterization of $\mathrm{CD}^{+}$and $\mathrm{CD}^{+} \mathrm{T}$ cells in control and $\mathrm{WT} \mathrm{CD} 8^{+} \mathrm{T}$

568 cell recipient PPRV infected IFNR KO mice showed a reduced expression of the

569 activation molecule CXCR3 and as well as a lymph node retention molecule CD62L

570 (Fig 6I). However in the spleen of $\mathrm{WT} \mathrm{CD}^{+} \mathrm{T}$ cell recipient mice the expression of

571 CXCR3 was increased but that of CD62L reduced by both $\mathrm{CD}^{+}$and $\mathrm{CD} 8^{+} \mathrm{T}$ cells

572 (Fig 6K). These results might mean suggest for the retention of $\mathrm{CD}^{+} \mathrm{T}$ cells in the

573 LNs of infected animals probably due to more chemokines build up and a less

574 efficient gradient generation for such chemokines to facilitate their exit and viral

575 control at the infection sites (25). A detailed analysis is currently underway.

576 We observed an aberrant activation profile of $\mathrm{T}$ cells in PPRV infected mice,

577 but a crucial role of functionally competent $\mathrm{CD}^{+} \mathrm{T}$ cells was evident in mitigating

578 PPRV pathogenesis.

\section{Identification of immunogenic $\mathrm{CD8}^{+} \mathrm{T}$ cell epitopes of PPRV in silico}

580 We identified immunogenic epitopes of PPRV that could induce specific

$581 \mathrm{CD}^{+} \mathrm{T}$ cells response in mice. All the structural proteins (heamagglutinin, matrix,

582 nucleocapsid and fusion proteins) of PPRV were analyzed for predicting $\mathrm{H}-2 \mathrm{~K}^{\mathrm{b}}$

583 restricted epitopes using IEDB database. We focused our analysis on the structural

584 proteins because such proteins are critical for the viral assembly and its envelope

585 formation (24). Peptides with low percentile ranks and the $\mathrm{IC}_{50}$ value of $<200 \mathrm{nM}$

586 were selected (Table S1). Out of the list generated, top 12 best ranking peptides (three

587 from each protein) were chosen for synthesis and further analysis (Fig 7A). The

588 peptides included in analysis were IVVRRTAGV, VAFNILVTL, FMYLFLLGV 
589 (matrix protein), FSAGAYPLL, ASFILTIKF, SSITTRSRL (Nucleocapsid protein),

590 VILDRERLV, IEHIFESPL, IGLVRDFGL (hemagglutinin protein) and

591 (AILTFLFLL, VAILTFLFL, SGGDFLAIL (fusion protein). The peptides were

592 subjected to in silico analysis. Molecular docking is one of the most frequently used

593 methods to predict the conformation of small-molecule ligands. Docking of selected

594 peptides from different proteins of PPRV against $\mathrm{H}-2 \mathrm{~K}^{\mathrm{b}}$ was performed and the

595 models were analyzed using Chimera tool. The energy parameters of the best fitting

596 structures among PPRV peptides were determined (Table S2 and S3). The best

597 docking results were provided by PPRV peptides FMYLFLLGV and FSAGAYPLL

598 with $\mathrm{H}-2 \mathrm{~K}^{\mathrm{b}}$. FMYLFLLGV peptide even yielded better docking scores then the

599 reference peptide FAPGNYPAL (SEV-9) of Sendai E virus (Fig 7B and D and Table

600 S2). Further analyses revealed phenylalanine residues at position 1 and 5 in

601 FMYLFLLGV peptide as the probable anchors. Similarly, for FSAGAYPLL peptide

602 phenylalanine at position 1 and proline at position 7 were predicted to be the most

603 probable anchors. Docking of peptides was also performed with class MHC molecule

604 of goat (CLA1) (Fig 7C and F, S10 and Table S3). CLA-I and H-2K ${ }^{\mathrm{b}}$ superposed near

605 perfectly at an RMSD value of $1.5 \mathrm{~A}$ (Fig 7E). The predicted peptides showed a

606 similar trend of docking with CLA-1 molecule. The anchor residues as well as the

607 docking scores of FMYLFLLGV and FSAGAYPLL peptides scored better in these

608 analyses (Fig 7E-F). Interestingly, all the epitopes displayed better docking with

609 CLA-1 than with $\mathrm{H}-2 \mathrm{~K}^{\mathrm{b}}$ indicating their immunogenicity in generating anti-viral

610 response against PPRV infection in the natural host, goats (Fig 7F). A total of 12

611 peptides were predicted that could potentially be immunogenic in mice as well as in

612 the natural host of PPRV goats. 
613 Assessing class I MHC stabilization potential of predicted PPRV epitopes using 614 acellular and cellular assays

615 We tested all top performing peptides for their class I MHC stabilization 616 potential using acellular and cellular assays. SIINFEKL, an Ova derived peptide with 617 known immunogenicity for $\mathrm{H}-2 \mathrm{~K}^{\mathrm{b}}$, was used as a positive control. In order to 618 measure the MHC stabilizing potential of predicted epitopes, we performed ELISA.

619 The heterotrimeric complex consisting of a photocleavable ligand, $\beta 2$ microglobulin 620 and $\mathrm{H}-2 \mathrm{~K}^{\mathrm{b}}$ was immobilized to solid phase by plate-coated streptavidin. UV displaced 621 conditional ligand and its replacement with the testing peptide yields a positive 622 reaction that can be detected by anti- $\beta 2$ microglobulin antibody (16). Fold change 623 values as compared to those obtained for SIINFEKL peptide for each of the PPRV 624 derivative peptides are shown in Fig 8A. Accordingly, FSAGAYPLL, IGLVRDFGL, 625 AILTFLFLL, SSITTRSRL, IVVRRTAGV, IEHIFESPL, VAFNILVTL, and 626 VILDRERLV displayed higher values as compared to other peptides (Fig 8A).

627 The peptides were also analysed for their class I MHC stabilizing activities 628 using transporter associated with antigen processing and presentation (TAP) deficient 629 RMA/S cells. Such cells express fewer molecules of class I MHCs on surface but the 630 exogenously added immunogenic peptides help stabilize their expression (26).

631 Different concentrations PPRV peptides were added to serum starved RMA/S cells 632 (Fig 8B-D). Out of 12 peptides, four peptides FMYLFLLGV (matrix protein), 633 FSAGAYPLL (nucleocapsid protein), IGLVRDFGL (hemagglutinin protein) and 634 AILTFLFLL (fusion protein) showed higher affinity for $\mathrm{H}-2 \mathrm{~K}^{\mathrm{b}}$ molecule and induced 635 more cells to express $\mathrm{H}-2 \mathrm{~K}^{\mathrm{b}}$ (Fig 8B-D). The results were dependent on the 636 concentrations of the peptides used (Fig 8B-D). Similar results were obtained when 637 the mean fluorescence intensity (MFI) values were measured for the expression of $\mathrm{H}-$ 
$6382 \mathrm{~K}^{\mathrm{b}}$ by each peptide (data not shown). Log $\mathrm{EC}_{50}$ values for AILTFLFLL,

639 FSAGAYPLL, IGLVRDFGL and FMYLFLLGV peptides were 2.098, 1.469, 1.228

640 and $1.268 \mu \mathrm{g} / \mathrm{ml}$, respectively (Fig 8D).

\section{Immunogenicity of PPRV peptides in PPRV infected or immunized mice}

642 We measured response of $\mathrm{CD}^{+} \mathrm{T}$ cells in PPRV infected and immunized

643 mice. As C57BL/6 mice were refractory to PPRV infection, we used a high dose of

644 PPRV (5x $10^{6}$ PFU) PPRV for infection. After 7 days, a boosting dose was given and

645 the analysis was done in blood samples three days later by measuring the numbers

646 and frequencies of class I MHC tetramer $\left(\mathrm{H}-2 \mathrm{~K}^{\mathrm{b}}-\mathrm{p}(\mathrm{PPRV})\right.$-tetramer). Our results

647 showed significantly more numbers of antigen-specific $\mathrm{CD}^{+} \mathrm{T}$ cells against

648 AILTFLFLL, FSAGAYPLL and IGLVRDFGL peptides of PPRV as compared to

649 those induced against FMYLFLLGV (Fig 9A-C). Tetramer positive $\mathrm{CD}^{+} \mathrm{T}$ cell

650 count was also high for FSAGAYPLL, IGLVRDFGL peptides in animals immunized

651 with the cocktail of four peptides (Fig. 9D-E). The functionality of PPRV specific

$652 \mathrm{CD}^{+} \mathrm{T}$ is currently being investigated.

653 Our results suggest an induction of $\mathrm{CD}^{+} \mathrm{T}$ cell response against predicted

654 PPRV epitopes. Therefore, our results also suggest that immunization with peptides

655 could represent a potential subunit vaccination approach for PPRV to investigate

656 properties of $\mathrm{CD}^{+} \mathrm{T}$ cells during PPRV infection in mice.

657

658 


\section{Discussion}

660 With ramped up efforts to eradicate PPRV by intensive vaccination programs,

661 it has become imperative to develop an accessible laboratory animal model to better

662 understand its pathogenesis and more importantly the immune correlates of protection

663 against the virus. Such investigation could enhance prospects of devising an

664 alternative vaccine strategies should a need arise. We undertook this study to develop

665 a laboratory mouse model to elucidate PPRV pathogenesis, the role of innate immune

666 cells and cytotoxic T cells in its control. We demonstrated the susceptibility of IFNR

667 KO mice to PPRV infection. The infected animals succumbed to PPRV infection

668 irrespective of the dose of inoculum and route of infection. The replicating viruses as

669 well as the derivative antigens were present abundantly in most of the critical organs

670 of infected mice. Neutrophils and macrophages likely served as the Trojan horse to

671 transport virus to the CNS to cause encephalitis while $\mathrm{CD}^{+} \mathrm{T}$ cells in addition to $\mathrm{NK}$

672 cells were protective in PPRV infected mice. We also discovered immunogenic

673 epitopes of PPRV and enumerated virus-specific $\mathrm{CD}^{+} \mathrm{T}$ cells in infected and

674 immunized mice C57BL/6 mice using an array of MHC tetramers. Our results showed

675 the infectivity of adult mice that can serve as a laboratory animal model for

676 investigating PPRV pathogenesis and further decipher protective role of $\mathrm{CD}^{+} \mathrm{T}$ cells.

677 PPRV, a member of morbilivirus genus of paramyxoviridae family, incurs

678 significant losses to animal husbandry sector in endemic areas (27). Therefore,

679 intensive vaccination programs are being adopted in many countries to eradicate the

680 virus. A laboratory mouse model would be useful not only to better understand the

681 contribution of cellular and molecular mediators in the viral of pathogenesis but also

682 to test the efficacy of anti-virals. One such class of host-derived molecules includes

683 type I IFNs that have potent anti-viral effects. We observed distinct expression pattern 
684 of type I IFNs induced by PPRV stimulated innate immune cells depending on the

685 dose of infecting virus, and the intrinsic properties of responding cells (RAW

686 macrophages versus bone marrow derived primary macrophages). These results could

687 suggest for a diversification in the function of type I IFNs. Such a phenomenon is

688 well documented for the activity of type I and type III IFNs that was shown to be

689 largely attributed to the expression pattern of their cognate receptors (28). While the

690 receptors for type I IFNs (IFNAR1 and IFNAR2) are ubiquitously present on most

691 cells, type III IFNRs (IFNL complex) are predominantly present in epithelial cells and

692 only a subset of innate immune cells such as neutrophils $(27,29)$. A dichotomy is also

693 known with the activity of type I IFNs i.e., IFN $\alpha$ and IFN $\beta(30)$. Furthermore, a

694 specific inhibition of IFNßsignaling by antibodies converted the course of a persistent

695 viral infection with LCMV clone 13 into an infection that could be efficiently

696 controlled in the acute phase (31). Therefore, further analysis to decipher the relative

697 roles of different species of type I IFNs in the protection against PPRV would be 698 valuable.

699 In WT animals the activity of NK cells might control PPRV infection 700 sufficiently and $\mathrm{CD}^{+}$and $\mathrm{CD} 8^{+} \mathrm{T}$ cells playing a subsidiary antiviral role (Fig 5).

701 We observed efficient infiltration of NK cells in the BAL and lung tissues but the 702 animals eventually succumbed to the infection (Fig 5I and M). These results 703 suggested a critical role of IFN signaling in the NK cells mediated control of PPRV 704 and the killing activity of such cells alone might not suffice to achieve viral control.

705 The expansion and the migration of $\mathrm{T}$ cells particularly of $\mathrm{CD}^{+} \mathrm{T}$ cells in PPRV 706 infected WT mice in comparisons to those in the IFNR KO mice could suggest for a 707 critical role played by IFN signaling in the efficient activation or the migration of 708 such cells which can then help efficient priming of $\mathrm{CD}^{+} \mathrm{T}$ cells. That the $\mathrm{CD} 4^{+} \mathrm{T}$ 
709 cell responses precede $\mathrm{CD}^{+} \mathrm{T}$ cells was shown earlier (32). Earlier reports also

710 suggested that an inefficient JAK/STAT signaling in $\mathrm{CD}^{+} \mathrm{T}$ cells that occur

711 following type I IFN ligation with their cognate receptors enhances the propensity of

712 such cells to undergo apoptosis by host factors such as the glucocorticoids. Multiple

713 studies have shown that microbial infections can actively engage hypothalamic

714 pituitary adrenal (HPA) axis to induce glucocorticoids able to induce the apoptosis of

$715 \mathrm{CD}^{+} \mathrm{T}$ cells (17). Whether or not PPR infection predominantly activate HPA axis is

716 not known currently. That $\mathrm{CD}^{+} \mathrm{T}$ cells are involved in anti-PPRV defense

717 mechanisms was shown by the adoptive transfer of $\mathrm{WT} \mathrm{CD} 8^{+} \mathrm{T}$ cells, isolated from

718 previously infected mice that resolved the infection (Fig 6).

719 With limited data available for PPRV cell and tissue tropism, its replication

720 was demonstrated in the lymphoid organs (6). The known receptor for PPRV are

721 SLAM family proteins (33). Our results demonstrated that the cells of innate immune

722 origin expanded upon PPRV infection in IFNR KO mice were susceptible to the viral

723 infection. Surprisingly innate immune cells such as neutrophils and macrophages

724 were potentially able to transfer virus to distal locations (Fig 3 and 4). The innate

725 immune cells express SLAM receptors abundantly and therefore their susceptibility to

726 PPRV infection could involve these receptors (33). The identification of a particular

727 receptor in the susceptibility of mice has not been explored and constitutes part of our

728 ongoing investigations. It would be interesting to explore whether PPRV replicates in

729 the innate immune cells of sheep and goats. If indeed such cells exhibit susceptibility

730 to PPRV, it might necessitate revisiting vaccination strategies to help achieve a

731 complete viral eradication. Neurovirulence and neuropathology induced by PPRV are

732 recently reported in goat kids and newly born BALB/c mice as well as CD1d

733 knockout mice, the latter induce inefficient NK cells responses $(22,23)$. However the 
734 susceptibility of IFNR KO mice to PPRV was not shown earlier. Our observations

735 could be more relevant for some herds that might have mutations in one or more

736 components of signaling pathways involving type I IFNs. Animals and humans with

737 signaling defects in pathways leading to type I IFN production are exceedingly

738 susceptible to viral infections $(21,34)$. We used a vaccine strain of PPRV that

739 induced a hundred percent mortality in IFNR KO mice and no apparent disease in WT

740 C57BL/6 mice. Whether or not the virulent strain of PPRV can induce the disease and

741 potent CTL response in WT mice is currently being investigated in our laboratory.

742 An initial encounter of host with viruses elicit type I IFN response, but for a

743 long term protection the optimal activity of $\mathrm{CD}^{+} \mathrm{T}$ cells is crucial in virus clearance

$744(17,35)$. This necessitates identifying class I epitopes that can be used to quantify and

745 assess functionality of such cells (11). Moreover, designing a vaccine against an

746 intracellular pathogen also requires information about immunogenic epitopes that can

747 also serve as subunit vaccine candidates. Screening of peptides of an antigen is best

748 done by in silico analysis as invariably a large number of linear amino acid sequences

749 need to be probed. The utility of class I MHC tetramers in staining antigen-specific

$750 \mathrm{CD}^{+} \mathrm{T}$ cells and discovering epitopes in a throughput manner is unmatched but has

751 not been adequately put to use particularly for animal pathogens $(18,36)$. The

752 prediction of peptide is necessary for diagnosis, formulating vaccines as well as for

753 analyzing the functionality of cells $(11,18,37)$. We discovered at least four

754 immunogenic epitopes from structural proteins of PPRV using in silico, ex vivo and in

755 vivo approaches. That the immunization of mice with a cocktail of peptides induced

756 PPRV specific $\mathrm{CD}^{+} \mathrm{T}$ cells constitute first such example for PPRV. Furthermore

757 such an approach provides impetus to subunit vaccine development. Our ongoing 
758 investigations would help decipher pathways in virus specific $\mathrm{CD} 8^{+} \mathrm{T}$ cells that could

759 help provide protection during acute as well as memory response. 


\section{References}

761 1. Diallo A, Minet C, Le Goff C, Berhe G, Albina E, Libeau G, Barrett T. 2007.

762 The threat of peste des petits ruminants: progress in vaccine development for

763 disease control. Vaccine 25:5591-5597.

764 2. Singh RK, Balamurugan V, Bhanuprakash V, Sen A, Saravanan P, Yadav MP. 765 2009. Possible control and eradication of peste des petits ruminants from India:

766 technical aspects. Vet Ital 45:449-462.

767 3. Kumar P, Tripathi BN, Sharma AK, Kumar R, Sreenivasa BP, Singh RP, Dhar

768 P, Bandyopadhyay SK. 2004. Pathological and immunohistochemical study of

769 experimental peste des petits ruminants virus infection in goats. J Vet Med Ser $770 \quad$ B 51:153-159.

771 4. Mahapatra M, Parida S, Egziabher BG, Diallo A, Barrett T. 2003. Sequence 772 analysis of the phosphoprotein gene of peste des petits ruminants (PPR) virus: 773 editing of the gene transcript. Virus Res 96:85-98.

774 5. Baron MD, Parida S, Oura CAL. 2011. Peste des petits ruminants: a suitable 775 candidate for eradication? Vet Rec 169:16-21.

776 6. Truong, T. Boshra, H. Embury-Hyatt, C. Nfon, C. Gerdts, V, Tikoo, S. Babiuk, 777 LA. Kara, P. Chetty, T. Mather, A. Wallace, DB. Babiuk S. 2014. Peste des 778 Petits Ruminants Virus Tissue Tropism and Pathogenesis in Sheep and Goats 779 following Experimental Infection. PLoS One 9:e87145.

780 7. Berhe, G. Minet, C. Le Goff, C. Barrett, T. Ngangnou, A. Grillet, C. Libeau, G. 781 Fleming, M. Black, DN. Diallo A. 2003. Development of a dual recombinant 782 vaccine to protect small ruminants against peste-des-petits-ruminants virus and 783 capripoxvirus infections. J Virol 77:1571-7.

784 8. Reed L, Muench H. 1938. A simple method of estimating fifty percent end 
points. Am J Epidemiol 27:493-497.

786 9. Wang C, Yu X, Cao Q, Wang Y, Zheng G, Tan TK, Zhao H, Zhao Y, Wang Y, Harris DCH. 2013. Characterization of murine macrophages from bone marrow, spleen and peritoneum. BMC Immunol 14:6.

10. Moutaftsi M, Peters B, Pasquetto V, Tscharke DC, Sidney J, Bui H-H, Grey H, Sette A. 2006. A consensus epitope prediction approach identifies the breadth of murine TCD8+-cell responses to vaccinia virus. Nat Biotechnol 24:817-819.

11. Calis JJA, Maybeno M, Greenbaum JA, Weiskopf D, De Silva AD, Sette A, 793 Keşmir C, Peters B. 2013. Properties of MHC class I presented peptides that enhance immunogenicity. PLoS Comput Biol 9.

795 12. Peters B, Bui H-H, Frankild S, Nielsen M, Lundegaard C, Kostem E, Basch D,

Lamberth K, Harndahl M, Fleri W. 2006. A community resource benchmarking predictions of peptide binding to MHC-I molecules. PLoS Comput Biol 2.

800

13. Remmert M, Biegert A, Hauser A, Söding J. 2012. HHblits: lightning-fast

801 iterative protein sequence searching by HMM-HMM alignment. Nat Methods $9: 173$.

14. Pettersen EF, Goddard TD, Huang CC, Couch GS, Greenblatt DM, Meng EC, Ferrin TE. 2004. UCSF Chimera—a visualization system for exploratory research and analysis. J Comput Chem 25:1605-1612.

15. Sehrawat S, Kirak O, Koenig P-A, Isaacson MK, Marques S, Bozkurt G, Simas JP, Jaenisch R, Ploegh HL. 2012. CD8(+) T cells from mice transnuclear for a TCR that recognizes a single H-2K(b)-restricted MHV68 epitope derived from gB-ORF8 help control infection. Cell Rep 1:461-71.

16. Chew SL, Or MY, Chang CXL, Gehring AJ, Bertoletti A, Grotenbreg GM. 
2011. Stability screening of arrays of major histocompatibility complexes on

811 combinatorially encoded flow cytometry beads. J Biol Chem 286:28466-

$812 \quad 28475$.

813 17. Kumar, D. Sehrawat S. 2019. Divergent Effects of a Transient Corticosteroid

814 Therapy on Virus-Specific Quiescent and Effector CD8+ T Cells. Front

815 Immunol 10:1521.

816 18. Rodenko B, Toebes M, Hadrup SR, Van Esch WJE, Molenaar AM, 817 Schumacher TNM, Ovaa H. 2006. Generation of peptide-MHC class I 818 complexes through UV-mediated ligand exchange. Nat Protoc 1:1120.

819 19. Freshney RI. 1987. Culture of animal cells: a manual of basic technique. New $820 \quad$ York: Alan R. Liss. Inc 1:177.

821 20. Kaur M, Kumar D, Butty V, Singh S, Esteban A, Fink GR, Ploegh HL, 822 Sehrawat, S. 2018. Galectin-3 regulates gamma-herpesvirus specific CD8 T 823 cell immunity. iScience 9, 101-119.

824 21. Rouse BT, Sehrawat S. 2010. Immunity and immunopathology to viruses: what 825 decides the outcome? Nat Rev Immunol 10:514-526.

826 22. Galbraith SE, McQuaid S, Hamill L, Pullen L, Barrett T, Cosby SL. 2002. 827 Rinderpest and peste des petits ruminants viruses exhibit neurovirulence in 828 mice. J Neurovirol 8:45-52.

829 23. Sahoo M, Dinesh M, Thakor JC, Baloni S, Saxena S, Shrivastava S, Dhama K, 830 Singh K, Singh R. 2020. Neuropathology mediated through caspase dependent 831 extrinsic pathway in goat kids naturally infected with PPRV. Microb Pathog 832 140J vi:103949.

833 24. Saravanan, S. Singh, RP. Balamurugan, P. Saravanan, S. Sen, Sahay, B. Sarkar, 834 J . Singh R. 2007. Production and Characterization of Neutralizing Monoclonal 
835

836

837

838

839

840

841

842

843

844

845

846

847

848

849

850

851

852

853

854

855

856

857

858

859

Antibodies Against Haemagglutinin Protein of peste des petits ruminants (PPR) Vaccine Virus. J Appl Anim Res 32:207-210.

25. Lund JM, Hsing L, Pham TT, Rudensky AY. 2008. Coordination of early protective immunity to viral infection by regulatory $\mathrm{T}$ cells. $30 ; 320(5880): 1220-4$.

26. Van Kaer, L. Ashton-Rickardt, P.G. Ploegh, H.L., Tonegawa S. 1992. TAP1 mutant mice are deficient in antigen presentation, surface class I molecules, and CD4-8+ T cells. Cell 71:1205-1214.

27. Kumar N, Barua S, Riyesh T, Tripathi BN. 2017. Advances in peste des petits ruminants vaccines. Vet Microbiol 206:91-101.

28. Galani IE, Triantafyllia V, Eleminiadou E-E, Koltsida O, Stavropoulos A, Manioudaki M, Thanos D, Doyle SE, Kotenko S V, Thanopoulou K. 2017. Interferon- $\lambda$ mediates non-redundant front-line antiviral protection against influenza virus infection without compromising host fitness. Immunity 46:875890.

29. Crotta, S. Davidson, S. Mahlakoiv, T. Desmet, CJ. Buckwalter, MR. Albert, ML. Staeheli, P. Wack A. 2013. Type I and Type III Interferons Drive Redundant Amplification Loops to Induce a Transcriptional Signature in Influenza-Infected Airway Epithelia. PLoS Pathog 9:e1003773.

30. Wang, Y. Swiecki, M. Cella, M. Alber, G. Schreiber, RD. Gilfillan, S. Colonna M. 2012. Timing and magnitude of type I interferon responses by distinct sensors impact CD8 T cell exhaustion and chronic viral infection. Cell Host Microbe 11:631-42.

31. Ng CT, Sullivan BM, Teijaro JR, Lee AM, Welch M, Rice S, Sheehan KC, Schreiber RD, Oldstone M. 2015. Blockade of interferon Beta, but not 
860 interferon alpha, signaling controls persistent viral infection. Cell Host Microbe

$861 \quad 17: 653-61$.

862 32. Nakanishi Y, Lu B, Gerard C, Iwasaki A. 2009 CTL mobilization to virus-

863 infected tissue requires CD4+ T cell help. Nature 26; 462(7272): 510-513.

864 33. Veillette A. 2006. Immune regulation by SLAM family receptors and SAP865 related adaptors. Nat Rev Immunol 6:56-66.

866 34. Sehrawat S, Kumar D, Rouse BT. 2018. Herpesviruses: Harmonious Pathogens

867 but Relevant Cofactors in Other Diseases? Front Cell Infect Microbiol 8:177.

868 35. Ahmed R, Kaech SM. 2001. Memory CD8+ T cell differentiation: initial 869 antigen encounter triggers a developmental program in naïve cells. Nat $870 \quad$ Immunol 2:415-422.

871 36. Flynn KJ, Belz GT, Altman JD, Ahmed R, Woodland DL, Doherty PC. 1998.

872 Virus-specific CD8+ T cells in primary and secondary influenza pneumonia.

$873 \quad$ Immunity 8:683-691.

874 37. Rammensee H-G, Bachmann J, Emmerich NPN, Bachor OA, Stevanović S. 875 1999. SYFPEITHI: database for MHC ligands and peptide motifs. $876 \quad$ Immunogenetics 50:213-219. 
879 Figure legends

880 Figure 1. PPRV pulsed murine macrophages mount a rapid IFN response.

881 Murine macrophages (RAW macrophages and primary bone marrow derived 882 macrophages) were pulsed with PPRV at low (1:1) and high (1:10) multiplicity of 883 infections (MOI) to measure IFN $\alpha$, IFN $\beta$ and IFN $\gamma$ response. The PPRV exposed 884 cells were collected at different times to isolate total RNA. cDNA synthesized was 885 measured for the expression of different IFNs by RT-qPCR. A-C. Fold change in the 886 expression of IFN $\alpha, \beta$ and $\gamma$ is shown by bar diagrams at $15 \mathrm{~min}, 30 \mathrm{~min}, 1 \mathrm{hr}$ and $6 \mathrm{hr}$. 887 D-F. BMDMs similarly analyzed for the expression of IFN $\alpha, \beta$ and $\gamma$ at indicated 888 time points. Bar diagrams show fold change in the expression of IFNs. The 889 experiments were repeated six times. One way ANOVA test was used for 890 determining the statistical significance and $\mathrm{p}$ values are represented as following; $\mathrm{p}$ $<0.05 *, \mathrm{p}<0.01 * *, \mathrm{p}<0.001 * * *$.

892 Figure 2. IFNR KO mice are susceptible to PPRV infection. A. The schematic of 893 experiments is shown. IFNR KO mice were i.p. infected with indicated doses of 894 PPRV and the survival analysis (B) and percentage change in body weight of mice 895 (C) from each group is shown. The level of statistical significance was determined by 896 Gehan-Breslow-Wilcoxon test and one-way ANOVA, respectively. Each data point 897 in the graph represents the average percent change in body weight at the indicated 898 dpi. Control animals were not infected with PPRV. D. Fluorescent microscopic 899 images show the presence of PPRV antigens in brain tissues of the infected IFNR 900 KO mice as detected by anti-PPRV $(\mathrm{H}) \mathrm{mAbs}$. E. Bar diagrams show PPRV titres as 901 represented by $\log 10 \mathrm{PFU} / \mathrm{g}$ of tissue when measured by plaque forming assays using 902 brain tissues of i.p., infected IFNR KO mice administered with varying doses. F-G. 903 IFNR KO mice were i.p. infected with $1.5 \times 10^{6}$ PFU of PPRV and different organs 
904 were collected 4dpi to measure the presence of viral antigens (F) and replicating

905 virus $(\mathrm{G})$ in different organs. F. Fluorescent microscopic images show the presence

906 of virus antigens in brain tissues of PPRV infected IFNR KO mice as detected by

907 anti-PPRV $(\mathrm{H})$ protein mAbs. G. Virus titers as represented by $\log 10 \mathrm{PFU} / \mathrm{g}$ of tissue

908 in heart, lung and liver is shown. Data represents the mean \pm SD of three replicates

909 of tissue samples. H. Virus titers as represented by $\log 10 \mathrm{PFU} / \mathrm{g}$ of tissue are shown

910 in different organs of IFNR KO mice infected with 1PFU of PPRV. I.

911 Histopathological changes in virus infected brain sections are shown. The

912 experiments were repeated three times with similar results. B-I. One way ANOVA

913 test was used for determining the statistical significance values and are represented

914 as following; $\mathrm{p}<0.05 *, \mathrm{p}<0.01 * *, \mathrm{p}<0.001^{* * *} . \mathrm{J}-\mathrm{M}$. Innate immune cells

915 were analyzed in the brain tissues of PPRV infected IFNR KO mice. The single cell

916 suspensions prepared from brain samples were stained with neutrophils

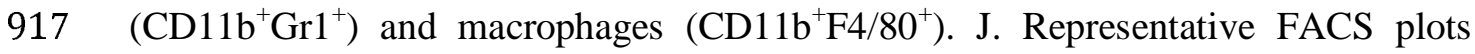

918 show the frequencies of $\mathrm{CD} 11 \mathrm{~b}^{+} \mathrm{Gr} 1^{+}$cells in control and PPRV infected mice. $\mathrm{K}$.

919 Bar diagrams show the cumulative data. L. Representative FACS plots show the

920 frequencies of $\mathrm{CD} 11 \mathrm{~b}^{+} \mathrm{F} 4 / 80^{+}$cells in control and PPRV infected mice. M. Bar

921 diagrams show the cumulative data. The experiments were repeated two times.

922 Student t test were used form determining the significance levels in control and

923 infected groups. $\mathrm{p}<0.05^{*}, \mathrm{p}<0.01 * *, \mathrm{p}<0.001 * * *$.

924 Figure 3. Determining PPRV infectivity of innate immune cells in IFNR KO

925 mice. IFNR KO mice were i.p infected with 100PFU of PPRV and the expansion as

926 well infectivity of innate immune cells was measured in spleen. A. Representative

927 FACS plots show the frequencies of $\mathrm{Gr}^{+}$cells among live cell gate in control and

928 PPRV infected mice. B. Bar diagrams show cumulative data for the frequencies of 
$929 \mathrm{Gr}^{+}$cells in control and PPRV infected mice. C-E. Intracellular staining was

930 performed as described in the material and methods sections to measure the presence

931 of PPRV antigens in $\mathrm{Gr}^{+}$cells using anti-PPRV $(\mathrm{H})$ and anti-PPRV $(\mathrm{N})$ protein

932 antibodies. C. Representative overlaid histograms show the frequency of PPRV

$933(\mathrm{H})^{+} \mathrm{Gr}^{+}$cells. D. Representative histograms show the percentage of PPRV

$934(\mathrm{~N})^{+} \mathrm{Gr} 1^{+}$cells. E. Bar diagrams show cumulative data as percent positive $\mathrm{Gr} 1^{+} \mathrm{PPRV}$

$935(\mathrm{H})^{+}$and PPRV $(\mathrm{N})^{+}$cells. F. Representative FACS plots show the frequencies of

$936 \mathrm{~F} 4 / 80^{+}$cells among live cell gate in control and PPRV infected mice. G. Bar

937 diagrams show cumulative data for the frequencies of $\mathrm{F} 4 / 80^{+}$cells in control and

938 PPRV infected mice. H-J. Intracellular staining was performed as described in the

939 materials and method section to measure the presence of PPRV antigens in $\mathrm{Gr}^{+}$cells

940 using anti-PPRV $\mathrm{H}$ protein and anti-PPRV-N protein mAbs. H. Representative

941 overlaid histograms show the frequency of PPRV $(\mathrm{H})^{+} \mathrm{F} 4 / 80^{+}$cells. I. Representative

942 histograms showing the percentage of PPRV $(\mathrm{N})^{+} \mathrm{F} 4 / 80^{+}$cells. J. Bar diagrams show

943 the percentage of $\mathrm{F} 4 / 80^{+}$cells expressing PPRV $(\mathrm{H})$ and PPRV $(\mathrm{N})$ proteins. K.

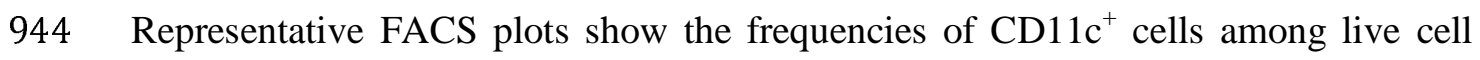

945 gate in control and PPRV infected mice. L. Bar diagrams show cumulative data for

946 the frequencies of $\mathrm{CD}_{11 \mathrm{c}^{+}}$cells in control and PPRV infected mice. M-O.

947 Intracellular staining was performed as described in the material and methods

948 sections to measure the presence of PPRV antigens in CD11 $\mathrm{c}^{+}$cells using anti-PPRV

$949 \mathrm{H}$ protein and anti-PPRV-N protein antibodies. M. Representative overlaid

950 histograms show the frequency of PPRV $(\mathrm{H})^{+} \mathrm{CD} 11 \mathrm{c}^{+}$cells. N. Representative

951 histograms show the percentage of PPRV $(\mathrm{N})^{+} \mathrm{CD} 11 \mathrm{c}^{+}$cells. O. Bar diagrams show

952 the percentage of $\mathrm{F} 4 / 80^{+}$cells expressing PPRV (H) and PPRV (N) proteins. The

953 experiments were repeated two times with four animals in each group. Different 
954 groups were analyzed by two-way ANOVA using Sidak's multiple comparison test.

955 Statistical significance values are represented as following; $\mathrm{p}<0.05 *, \mathrm{p}<0.01 * *$, $956 \mathrm{p}<0.001 * * *$.

957 Figure 4. Innate immune cells serve as the carrier of PPRV to brain tissues.

958 FACS sorted neutrophils, macrophages and dendritic cells from CD45.1 ${ }^{+}$C57BL/6

959 mice were pulsed with PPRV and after washing transferred into CD45.2 ${ }^{+}$IFNR KO

960 mice. At 4dpi, brain tissue staining was done with CD45.1 and CD45.2 markers. A.

961 Representative FACS plots depict the frequencies of donor cells in processed brain

962 tissue suspensions. B. Bar diagrams shown the cumulative frequencies of frequencies

963 expanded donor cells recovered from brain suspensions. For each group of recipients

964 three animals were used and the experiments were performed two times. C. FACS

965 sorted macrophages $\left(\mathrm{F} 4 / 80^{+\mathrm{ve}}\right)$, neutrophils $\left(\mathrm{Gr} 1^{+\mathrm{ve}}\right)$ and dendritic cells $\left(\mathrm{CD} 11 \mathrm{c}^{+\mathrm{ve}}\right)$

966 from CD45.1 ${ }^{+}$C57BL/6 mice were pulsed with PPRV for $1 \mathrm{hr}$ and transferred in

967 IFNR KO mice. The recipients were monitored for their body weights and morbidity.

968 D-E. FACS sorted macrophages $\left(\mathrm{F} 4 / 80^{+\mathrm{ve}}\right)$, neutrophils $\left(\mathrm{Gr}^{\mathrm{ve}}\right)$ and dendritic cells

$969\left(\mathrm{CD} 11 \mathrm{c}^{+\mathrm{ve}}\right)$ from CD45.1 ${ }^{+}$C57BL/6 mice were pulsed with PPRV for $1 \mathrm{hr}$. After

970 washings, cells were stained to determine the presence of surface or intracellular

971 viral antigens. Representative FACS plots show PPRV $(\mathrm{H})^{+\mathrm{ve}}$ cells for each cell type.

972 For gating FACS plots, fluorescent minus one (FMO) parameter were used. E. Bar

973 diagrams show cumulative data for $\mathrm{PPRV}^{+\mathrm{ve}}$ cells. The experiments were repeated

974 two more times. One way ANOVA or Student $t$ test were done for determining the

975 statistical significance values and are represented as following; $p<0.05 *$, p $<0.01$

$976 * *, \mathrm{p}<0.001 * * *$.

977 Figure 5. IFNR KO mice infected with PPRV develop lung pathologies and

978 mount innate as well as adaptive immune responses. A. IFNR KO and WT 
979 C57BL/6 mice were infected with varying doses of PPRV via intranasal route and

980 animals were analyzed for their survival, change in body weights. The level of

981 statistical significance was determined by Gehan-Breslow-Wilcoxon test and one-

982 way ANOVA, respectively. Terminally anaesthetized animals were analyzed for

983 measuring the cellular infiltration in BAL, lungs and lymphoid organs at $7 \mathrm{dpi}$. The

984 FACS plots for gating strategy and representative plots from different groups of

985 animals are shown in supplementary Fig S3-6. B. Percent change in body weights of

986 WT and IFNR KO mice infected with PPRV is shown. C-E. The frequencies of

987 leukocytes $\left(\mathrm{CD} 45^{+}\right.$cells) are shown in the BAL (C), lungs (D) and brain tissues (E)

988 of infected WT and IFNR KO mice. F. Bar diagrams show the percentage of CD4 $4^{+}$

989 and $\mathrm{CD}^{+} \mathrm{T}$ cells in the spleens of infected animals. G-J. Frequencies of

990 macrophages $\left(\mathrm{CD} 11 \mathrm{~b}^{+} \mathrm{F} 4 / 80^{+}\right)(\mathrm{G})$, neutrophils $\left(\mathrm{CD} 11 \mathrm{~b}^{+} \mathrm{Gr} 1^{+}\right) \quad(\mathrm{H}), \quad \mathrm{NK}$ cells

$991\left(\mathrm{NK} 1.1^{+}\right)(\mathrm{I})$ and $\mathrm{T}$ cells $(\mathrm{J})$ are shown in the BAL of infected animals by bar

992 diagrams. K-N. Frequencies of macrophages $\left(\mathrm{CD} 11 \mathrm{~b}^{+} \mathrm{F} 4 / 80^{+}\right)(\mathrm{K})$, neutrophils

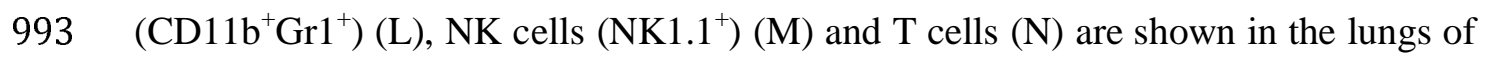

994 infected animals by bar diagrams. O-P. Frequencies of macrophages

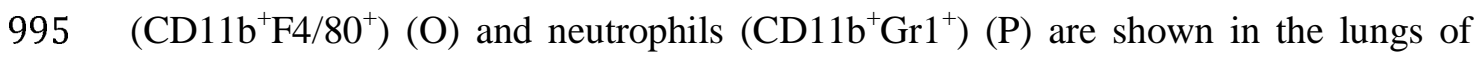

996 infected animals by bar diagrams. Q-V. Frequencies of macrophages

$997\left(\mathrm{CD}_{\left.11 \mathrm{~b}^{+} \mathrm{F} 4 / 80^{+}\right)}(\mathrm{Q})\right.$, neutrophils $\left(\mathrm{CD}_{\left.11 \mathrm{~b}^{+} \mathrm{Gr} 1^{+}\right)}\right)$(R) and the phenotypic

998 characterization $\mathrm{CD}^{+} \mathrm{T}$ cells $(\mathrm{S}$ and $\mathrm{T})$ and $\mathrm{CD}^{+} \mathrm{T}$ cells $(\mathrm{U}-\mathrm{V})$ for the indicated

999 markers are shown in the MLN of infected animals by bar diagrams. W-Z.

1000 Frequencies of macrophages $\left(\mathrm{CD} 11 \mathrm{~b}^{+} \mathrm{F} 4 / 80^{+}\right)(\mathrm{W})$ and neutrophils $\left(\mathrm{CD} 11 \mathrm{~b}^{+} \mathrm{Gr} 1^{+}\right)$

1001 (X) and NK cells (Y) are shown in the spleen of infected animals by bar diagrams. Z.

1002 Activation profile of splenic $\mathrm{CD}^{+} \mathrm{T}$ cells is shown by bar diagram. The experiments

1003 were repeated three times. The data was analyzed by two-way ANOVA was 
1004 performed for determining the statistical significance values. The levels of

1005 significance are represented as following; $\mathrm{p}<0.05 *, \mathrm{p}<0.01 * *, \mathrm{p}<0.001 * * *$.

1006 Figure 6. WT $\mathrm{CD8}^{+} \mathrm{T}$ cells delay mortality in PPRV infected IFNR KO mice. A

1007 schematic of the experiments is shown. $5 \times 10^{6}$ of $\mathrm{CD}^{+} \mathrm{T}$ cells from naïve or

1008 previously PPRV infected WT mice were transferred into IFNR KO mice. Next day,

1009 the recipient animals were infected with PPRV $\left(10^{4} \mathrm{PFU}\right)$. The disease progression,

1010 survival and cellular analysis of immune cells were performed. B. The survival in

1011 different groups of animals is shown. The results were analyzed by Gehan-Breslow-

1012 Wilcoxon test. C. Percent change in body weight of mice from each group is shown.

1013 The level of statistical significance was determined by Two-way ANOVA . D-E. The

1014 frequencies of leukocytes $\left(\mathrm{CD} 45^{+}\right.$cells) in BAL (D) and lungs (E) of infected mice

1015 are shown by bar diagrams. F-G. The frequencies of macrophages $\left(\mathrm{CD}_{11 \mathrm{~b}}{ }^{\mathrm{F}} \mathrm{F} / 80^{+}\right)$,

1016 neutrophils $\left(\mathrm{CD} 11 \mathrm{~b}^{+} \mathrm{Gr} 1^{+}\right)$, NK cells $\left(\mathrm{NK} 1.1^{+}\right)$and $\mathrm{T}$ cells (both $\mathrm{CD} 4^{+}$and $\mathrm{CD} 8^{+} \mathrm{T}$

1017 cells) are shown in the BAL (F) and lungs (G) of infected animals by bar diagrams.

$1018 \mathrm{H}$. The frequencies of macrophages $\left(\mathrm{CD} 11 \mathrm{~b}^{+} \mathrm{F} 4 / 80^{+}\right)$, neutrophils $\left(\mathrm{CD} 11 \mathrm{~b}^{+} \mathrm{Gr} 1^{+}\right), \mathrm{NK}$

1019 cells $\left(\mathrm{NK} 1.1^{+}\right)$, $\mathrm{T}$ cells $\left(\mathrm{CD} 4^{+}\right.$and $\mathrm{CD} 8^{+} \mathrm{T}$ cells) are shown in the MLNs of infected

1020 animals by bar diagrams. I. The phenotypic characterization $\mathrm{CD} 4^{+} \mathrm{T}$ cells and $\mathrm{CD} 8^{+}$

$1021 \mathrm{~T}$ cells for the indicated markers are performed and the percent positive cells

1022 frequencies for the indicated markers are shown for MLN of infected animals by bar

1023 diagrams. J. The frequencies of macrophages $\left(\mathrm{CD} 11 \mathrm{~b}^{+} \mathrm{F} 4 / 80^{+}\right)$, neutrophils

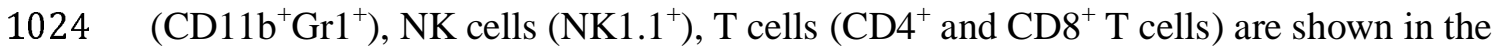

1025 MLNs of infected animals by bar diagrams. K. The phenotypic characterization

$1026 \mathrm{CD}^{+} \mathrm{T}$ cells and $\mathrm{CD}^{+} \mathrm{T}$ cells for the indicated markers were performed and the

1027 frequencies of percent positive cells for the indicated markers are shown for spleen

1028 of infected animals by bar diagrams. The experiments were performed three times. 
1029 The data was analysed by two-way ANOVA for determining the statistical

1030 significance values and are represented as following; $\mathrm{p}<0.05 * \mathrm{p}<0.01 * *, \mathrm{p}<$

$10310.001 * * *$.

1032 Figure 7. Molecular docking reveals docking of predicted peptides binding with

$1033 \mathbf{H}-\mathbf{H K}^{\mathbf{b}}$ and CLA-I. A. High scoring peptides and their origin of PPRV protein are

1034 tabulated. B. The docking scores of each peptide with $\mathrm{H}-2 \mathrm{~K}^{\mathrm{b}}$ are shown. C. The

1035 docking scores of each peptide with goat class I MHC (CLA-1) are shown by bar

1036 diagrams. D. Selected peptides for further evaluation in ex vivo and in vivo assays

1037 with their predicted molecular docking scores are shown. E. H-2K $\mathrm{K}^{\mathrm{b}}$ and CLA-1 were

1038 superimposed at RMSD value of 1.5A. F. A comparative analysis of docking scores

1039 of $\mathrm{H}-2 \mathrm{~K}^{\mathrm{b}}$ and CLA-I for the predicited PPRV peptides is shown.

1040 Figure 8. Immunogenicity of predicted peptides of PPRV was determined by in

1041 vitro assays. A. An ELISA was performed for measuring the stabilization of $\mathrm{H}-2 \mathrm{~K}^{\mathrm{b}}$

1042 monomers by synthetic peptides predicted to be immunogenic. The bar diagrams

1043 show folds change values for $\mathrm{H}-2 \mathrm{~K}^{\mathrm{b}}$ positive cells for the respective peptides as

1044 compared to the control peptide. B. Representative overlay histograms for different

1045 concentrations $(50 \mu \mathrm{g} / \mathrm{ml}, 25 \mu \mathrm{g} / \mathrm{ml}, 12.5 \mu \mathrm{g} / \mathrm{ml}$ and $6.25 \mu \mathrm{g} / \mathrm{ml})$ of indicated peptides

1046 show their ability to stabilize surface MHC molecules. The values represent the

1047 percent positive cells at different concentrations of peptides. C. Bar diagrams show

1048 percent $\mathrm{H}-2 \mathrm{~K}^{\mathrm{b}}$ positive cells for different concentrations of the indicated peptides. D.

1049 Line graph shows $\log \mathrm{EC}_{50}$ values for different peptides for stabilizing $\mathrm{H}-2 \mathrm{~K}^{\mathrm{b}}$ in

1050 pulsed RMA/s cells. Student t test were performed for determining the statistical

1051 significance values and are represented as following; $\mathrm{p}<0.05 *, \mathrm{p}<0.01 * *, \mathrm{p}<$

$10520.001 * * *$. 
1053 Figure 9. PPRV infected and PPRV-peptide immunized WT C57BL/6 mice

1054 expand virus-specific CD8 $^{+}$T cells. A-C. WT C57BL/6 mice (n=5) were i.p.

1055 infected with $5 \times 10^{6}$ PFU of PPRV at an interval of 7 days. The analysis of the

1056 expanded cells was performed three days later by measuring the frequencies PPRV-

1057 specific $\mathrm{CD}^{+} \mathrm{T}$ cells by staining with arrays of tetramers. A. Representative FACS

1058 plots shown the frequencies of class I MHC tetramer positive cells for the indicated

1059 peptides. B. Frequencies of PPRV-specific $\mathrm{CD}^{+} \mathrm{T}$ cells are shown by bar diagrams.

1060 C. The number of cells/million of PBMCs is shown by bar diagrams. D-E. C57BL/6

1061 mice $(n=4)$ were immunized either with the cocktail of peptide (AILTFLFLL,

1062 FMYLFLLGV, FSAGAYPLL and IGLVRDFGL) each with 5 $\mu \mathrm{g} / \mathrm{mouse}$ in complete

1063 Freund's adjuvant via subcutaneous route. After two weeks, a second injection of the

1064 same concentration was administered as an emulsion with incomplete Freund's

1065 adjuvant. Three days later the frequencies of peptide specific $\mathrm{CD}^{+} \mathrm{T}$ cells were

1066 measured by tetramer staining of PBMCs. D. Representative FACS plots show the

1067 frequencies of PPRV-specific $\mathrm{CD}^{+} \mathrm{T}$ cells. E. The number of cells/million of

1068 PBMCs is shown by bar diagrams. The experiments were repeated two times and the

1069 statistical significance was measured by Student t test. $\mathrm{p}<0.05 *$, p $<0.01 * *$. 
Figure 1

A

IFN a

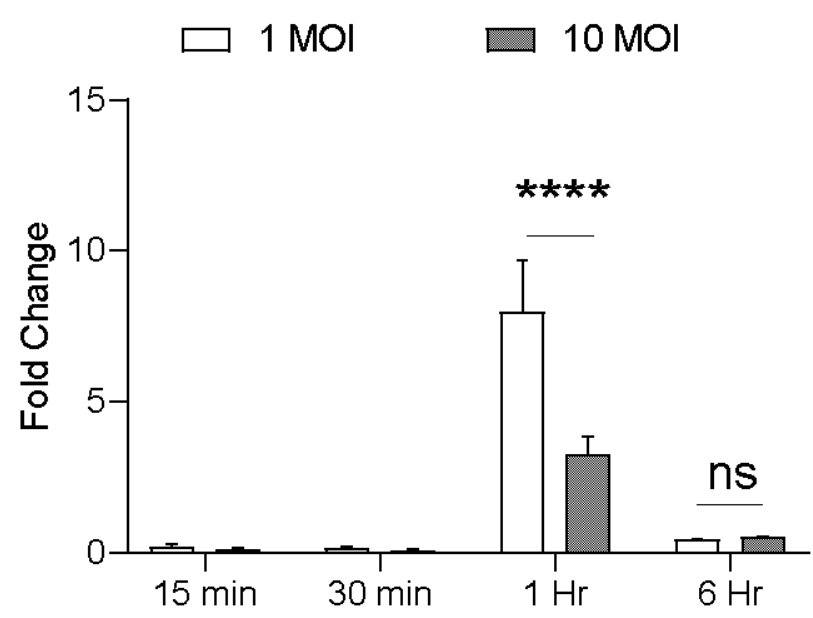

D
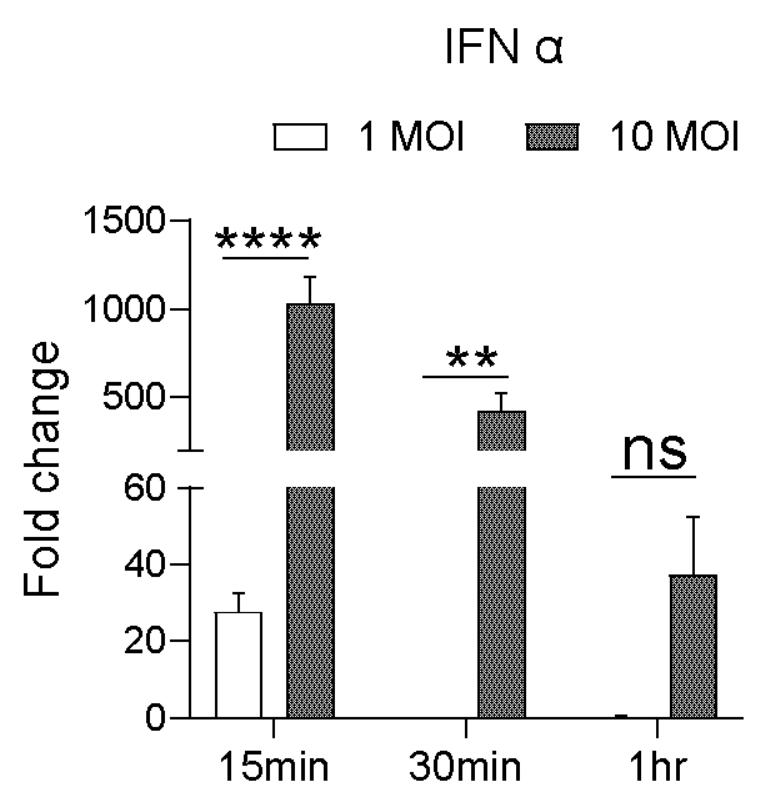

B

C

IFN $\beta$
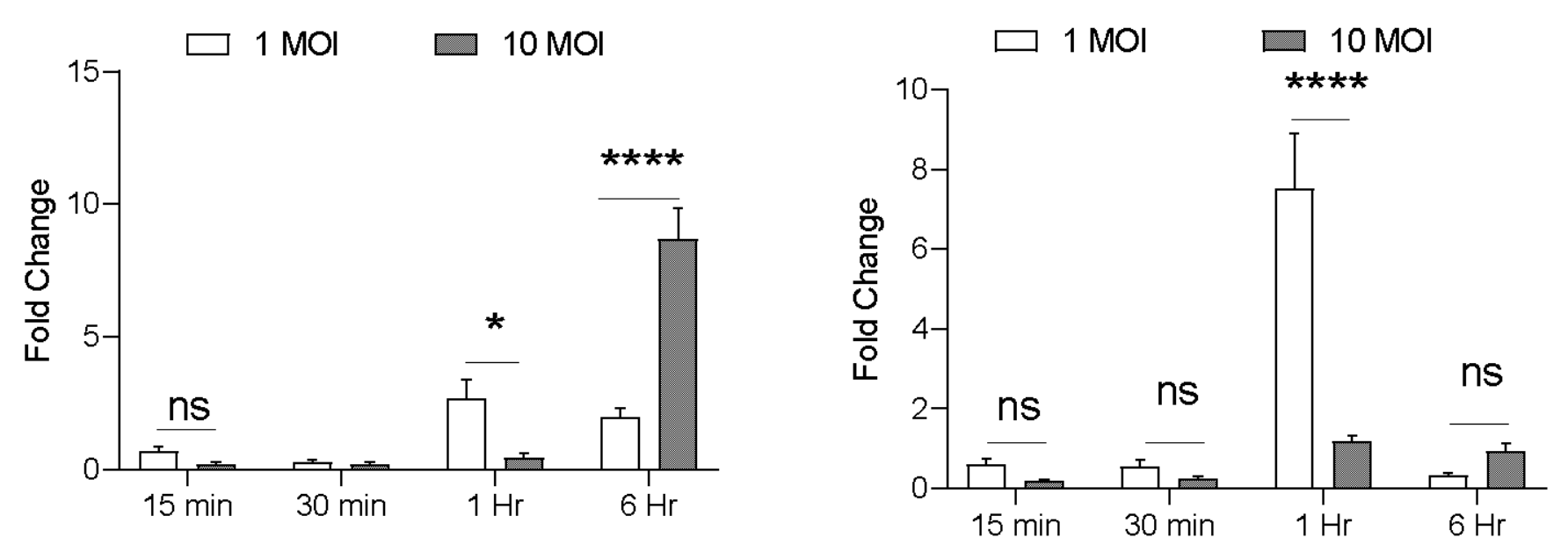

E

IFN $\beta$

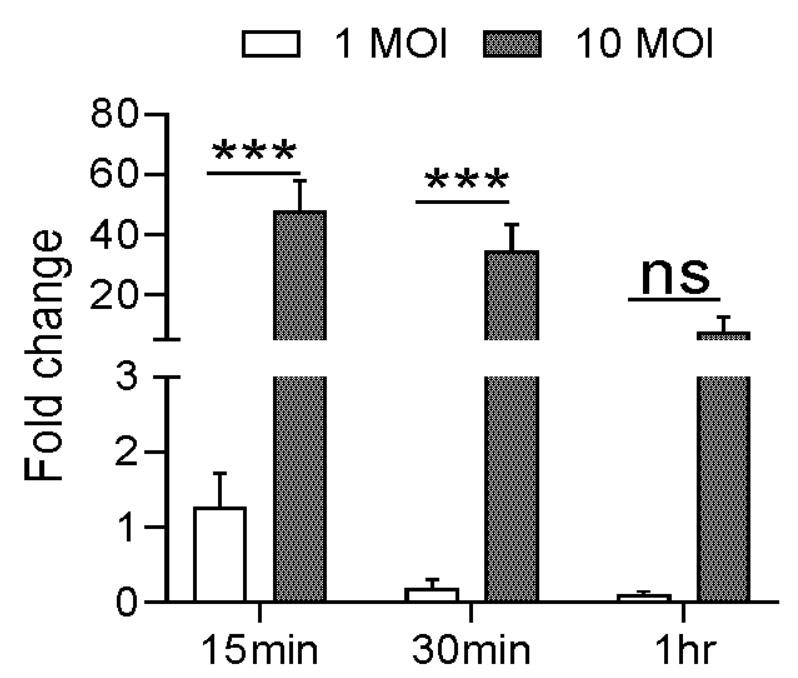

F

IFN $\gamma$

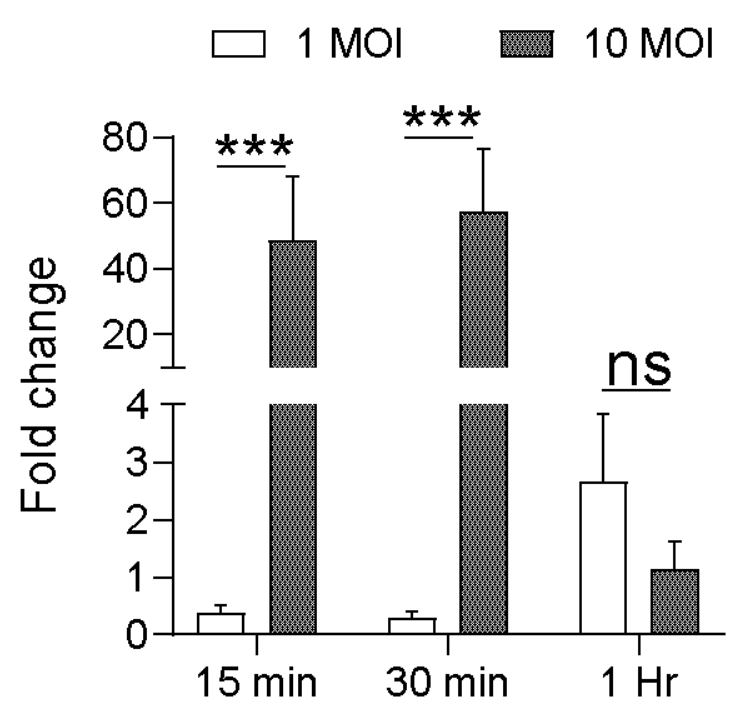


A

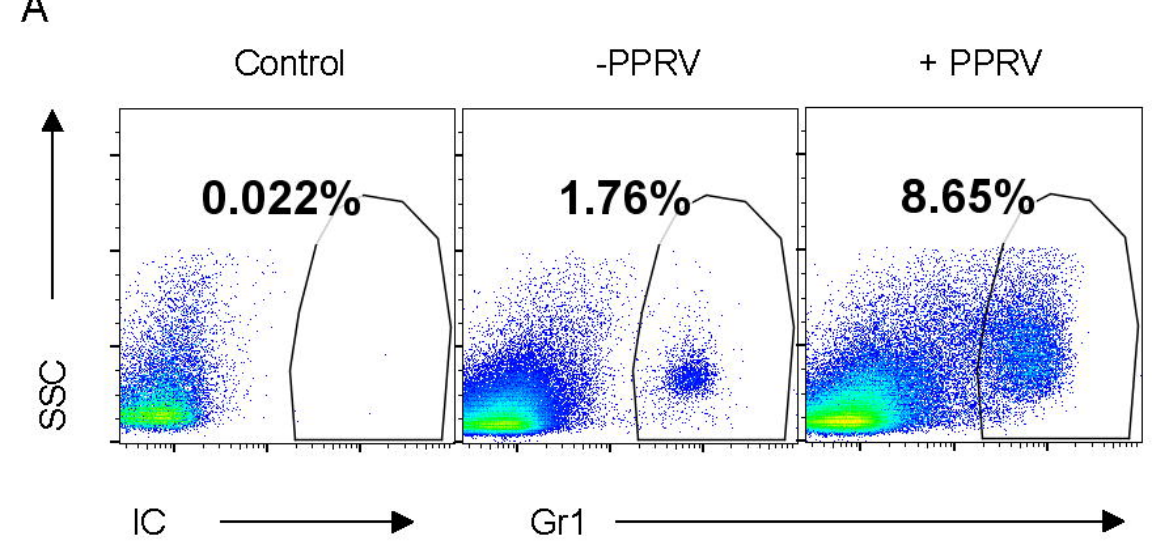

F

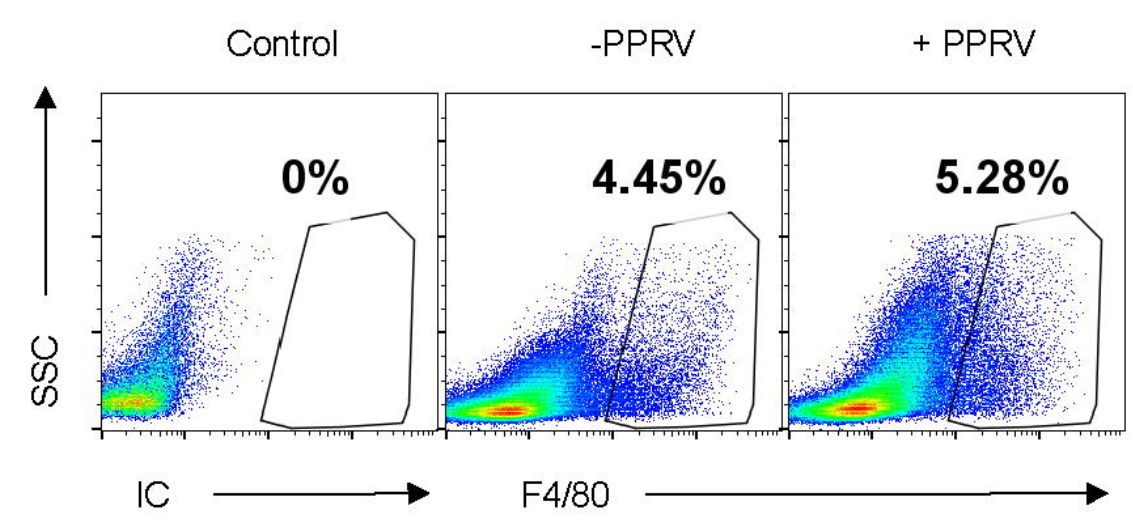

K

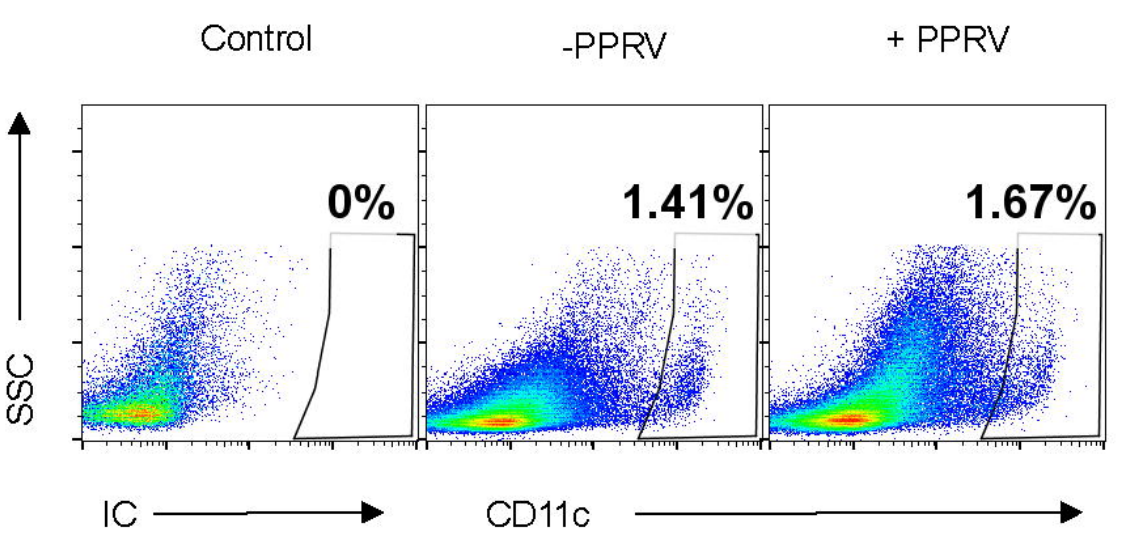

B

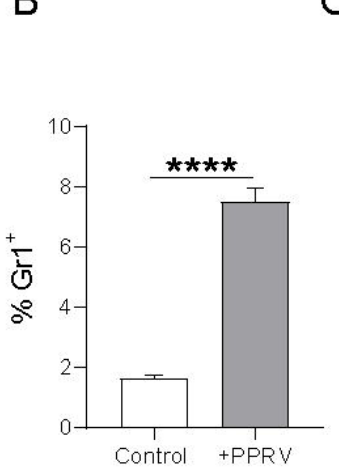

C

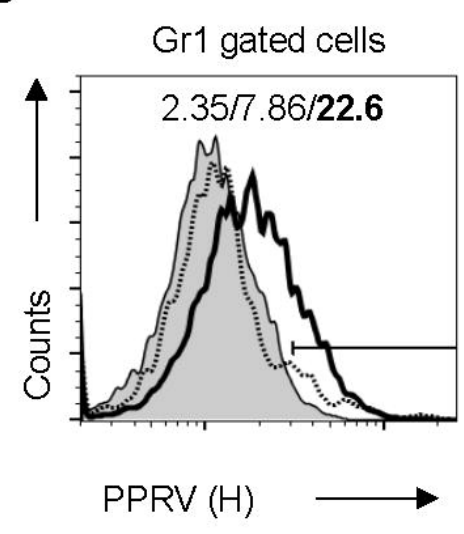

G

$\mathrm{H}$

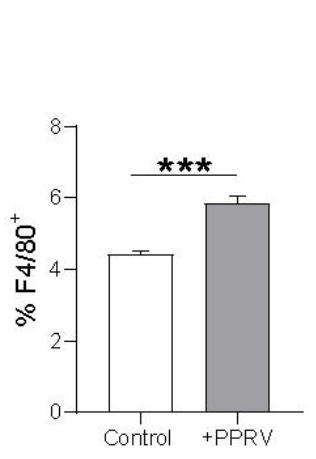

L

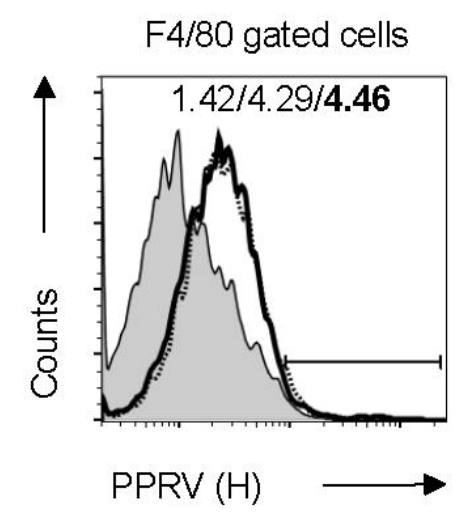

M

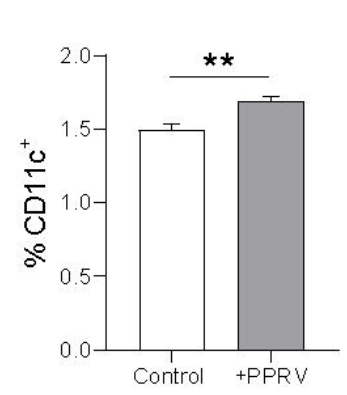

CD11c gated cells
D

I

N

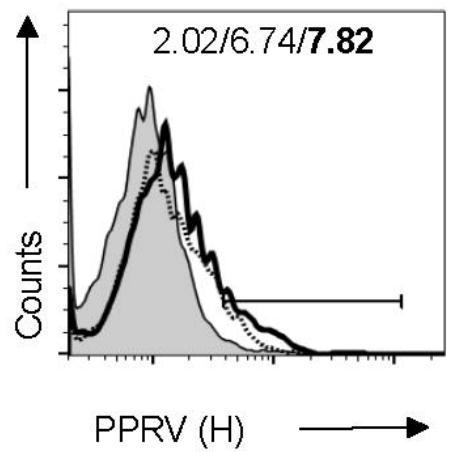

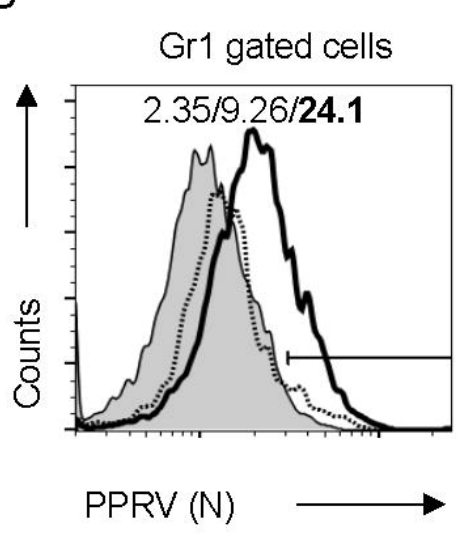

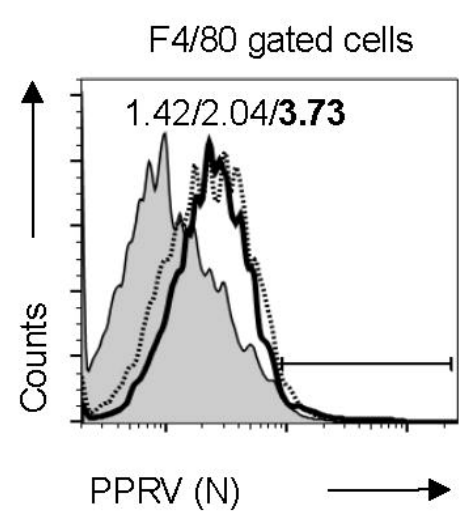

E

$\square$ Control $\square$ +PPRV

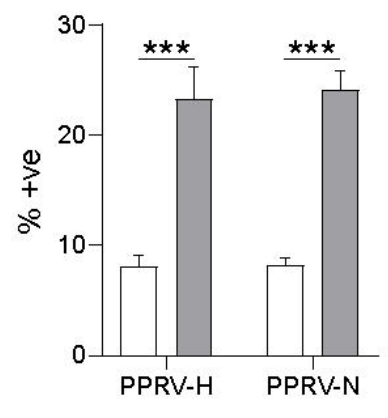

J

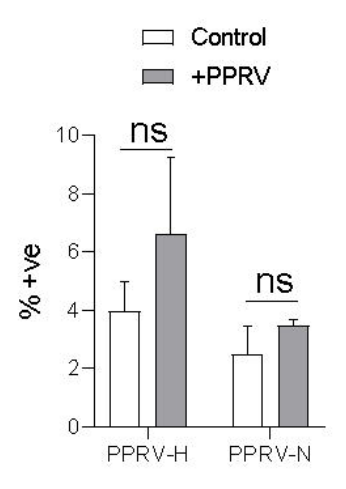

O

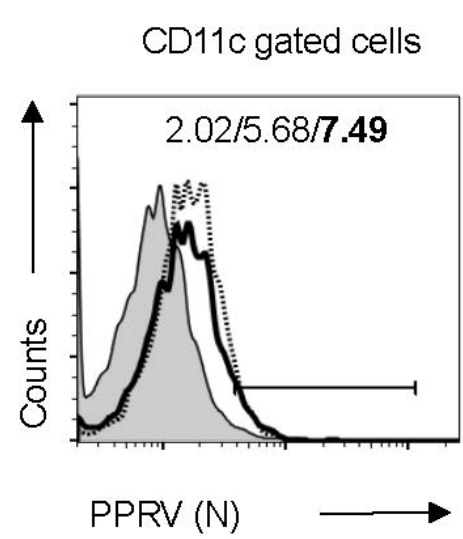


A

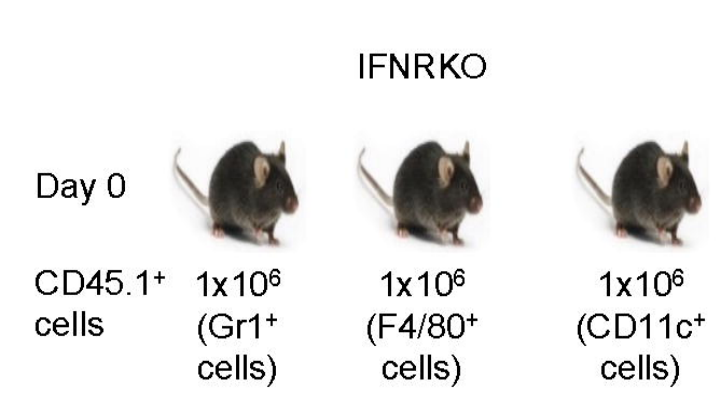

Day 1

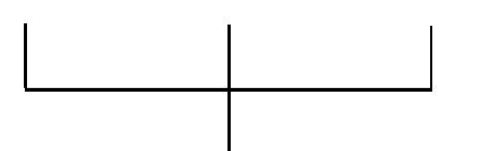

Day

Body Wt, Cellular analysis
B

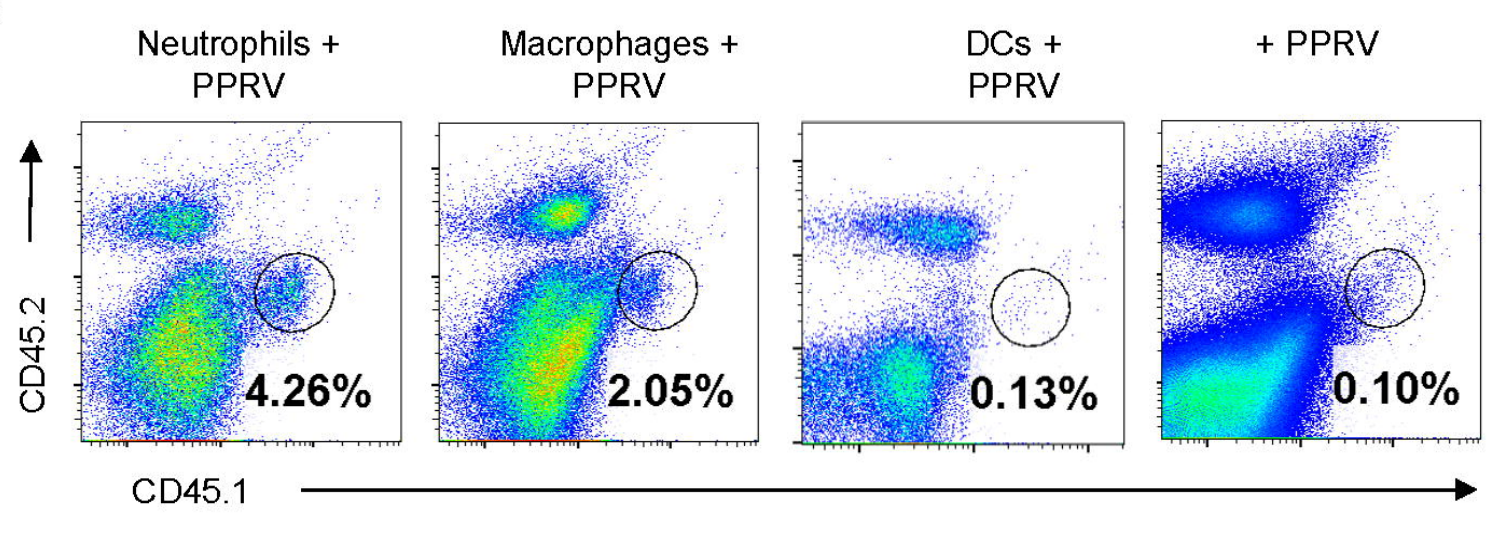

C

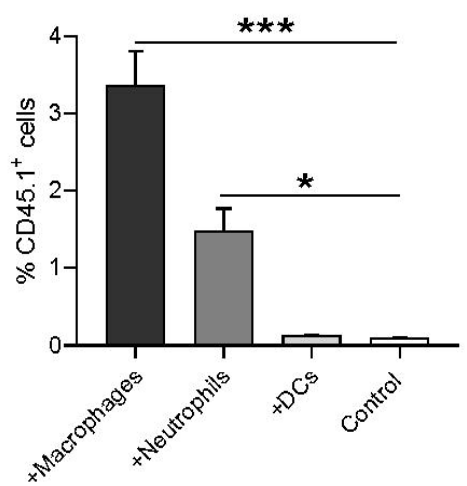

D

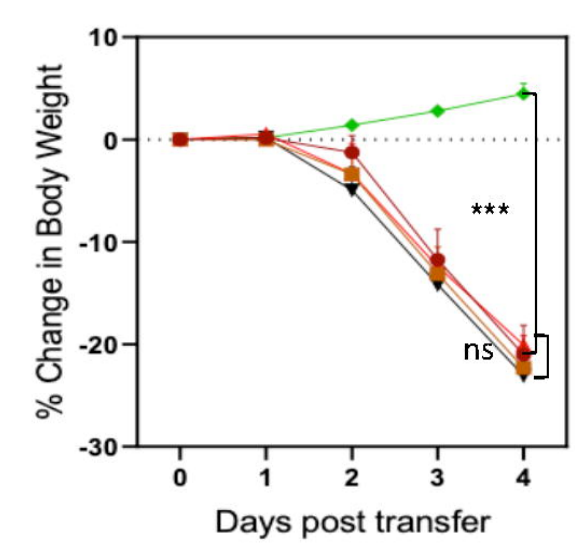

F Control Surface Intracellular

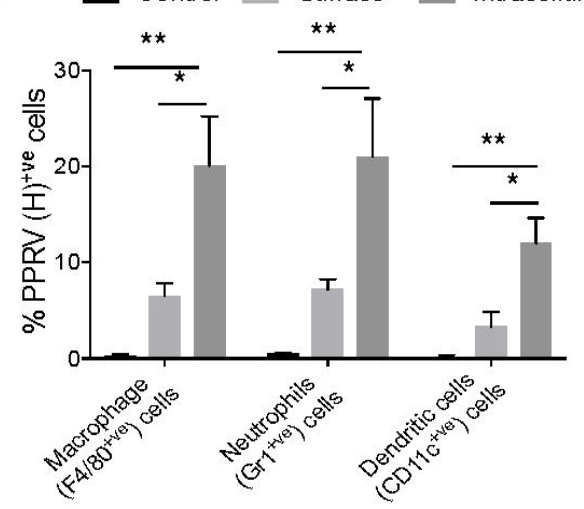

$\bullet$ DCs

- Mन्S

- Neutrophils

† PPRV

- Control
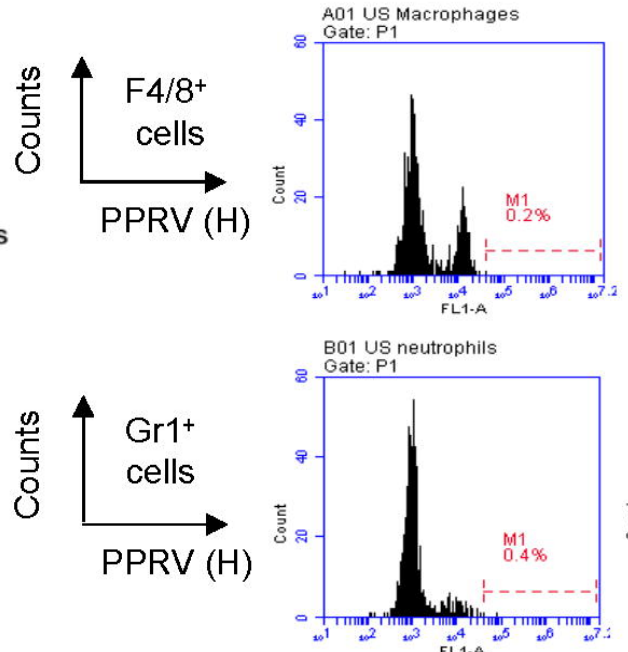

Surface Stained

IC Stained

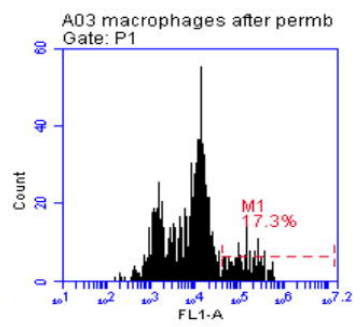

Transferred cells

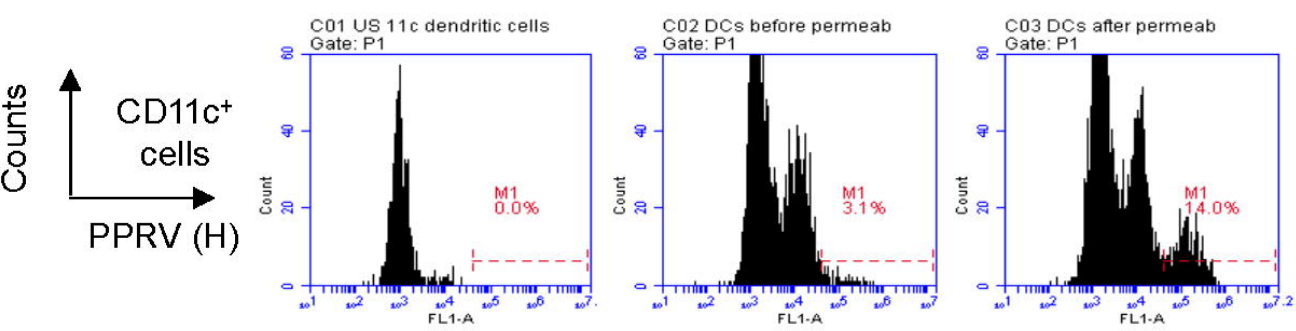


Figure 5

A

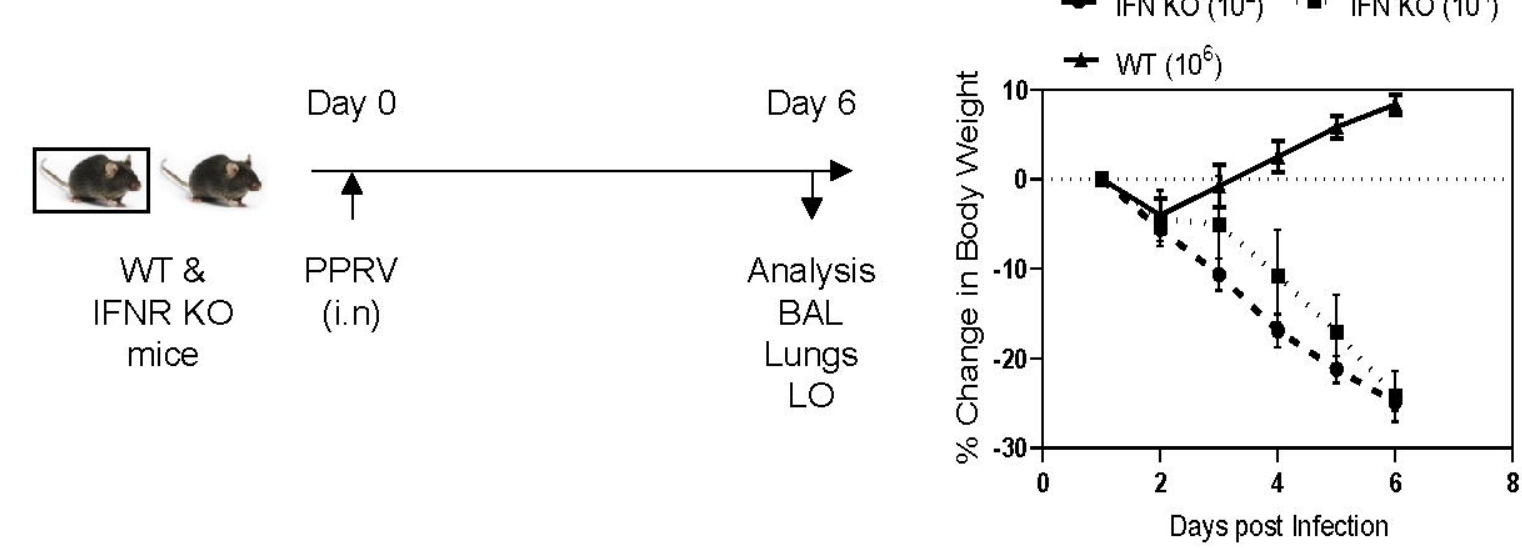

C

D

BAL

Lungs

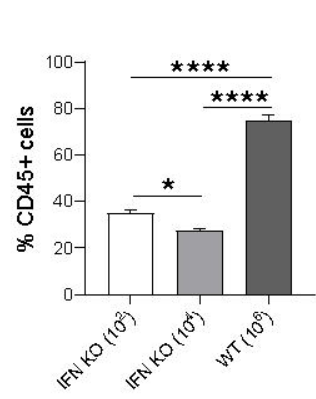

E

Brain

F

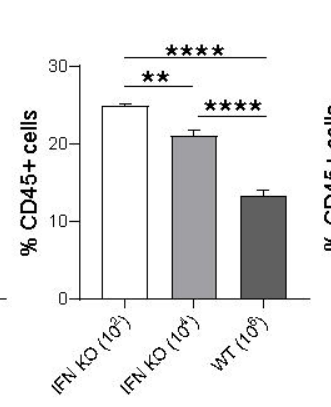

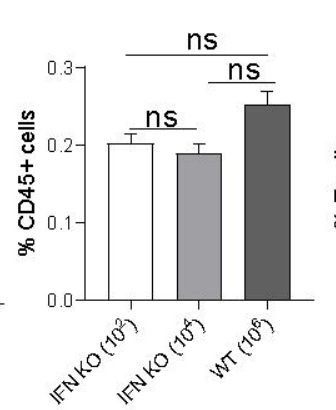

Spleen

口 IFN KO $\left(10^{2}\right)$ 口 IFN KO $\left(10^{4}\right)$

- WT $\left(10^{6}\right)$

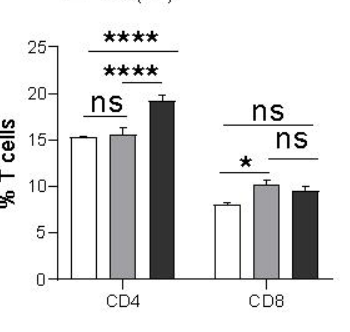

CD4

G

\section{BAL}

H

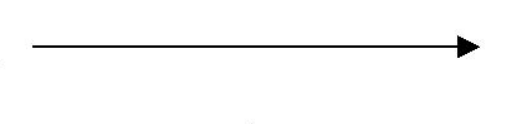

J
Lungs

M
Brain

$\mathrm{P}$
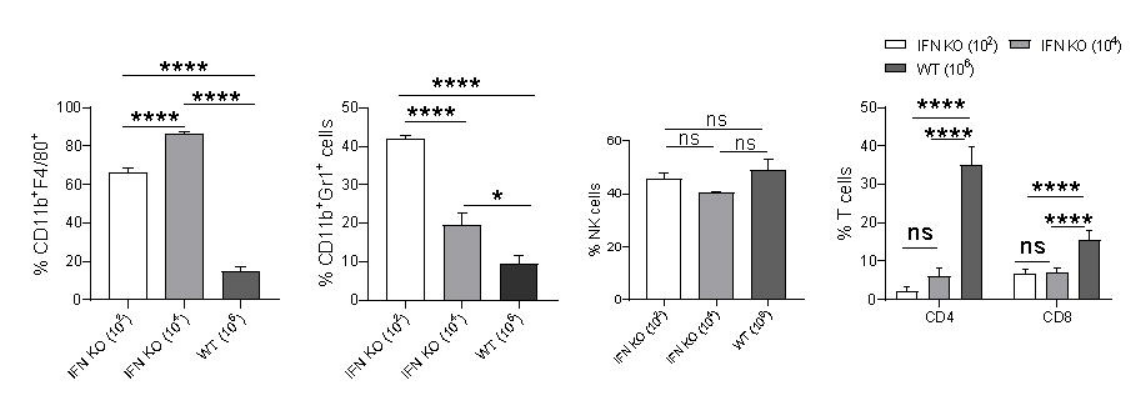

L

N

0

ㅁ IFNKO (102) 口 IFN KO (104)
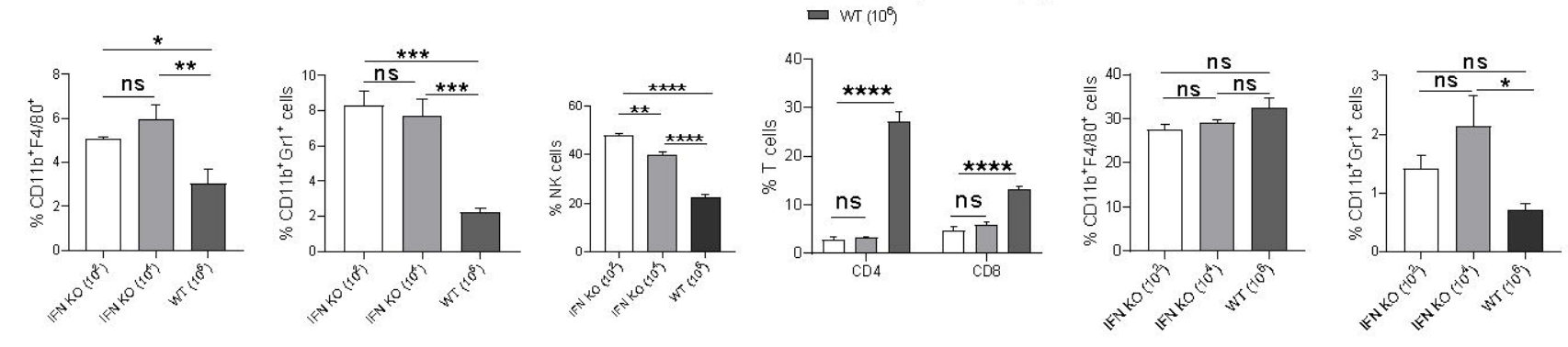

MLN
$T$

U

Spleen

V W

x

z
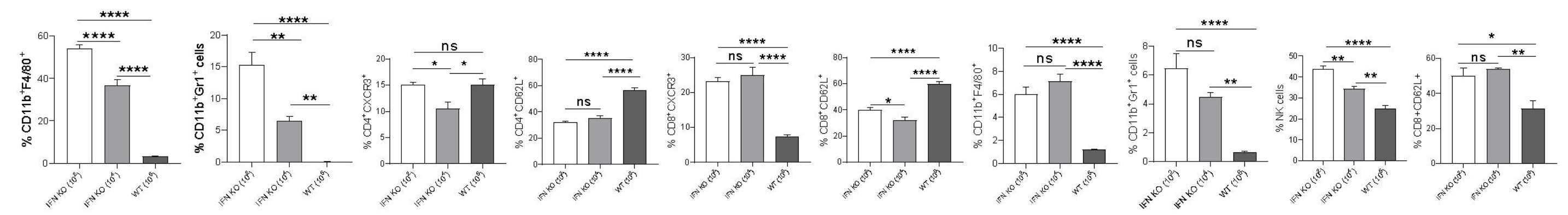
A

\begin{tabular}{|c|c|}
\hline $\begin{array}{c}\text { PPRV } \\
\text { PROTEIN }\end{array}$ & H-2K' \\
\hline Fusion & $\begin{array}{c}\text { AILTFLFLL } \\
\text { VAILTFLFL } \\
\text { SGGDFLAIL }\end{array}$ \\
\hline Nucleocapsid & $\begin{array}{c}\text { ASFILTIKF } \\
\text { SSITTRSRL }\end{array}$ \\
\hline Hemagglutinin & $\begin{array}{l}\text { FILDRERLV } \\
\text { IEHIFESPL } \\
\text { IGLVRDFGL }\end{array}$ \\
\hline Matrix & IVVRRTAGV \\
& VAFNILVTL \\
& FMYLLLGV \\
\hline
\end{tabular}

B

离

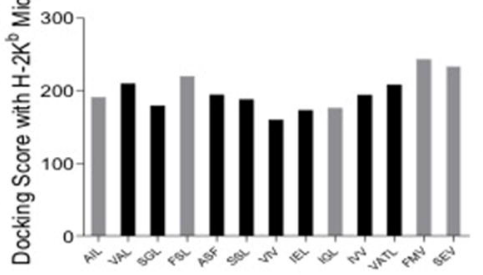

Predicted PPRV Peptides

E

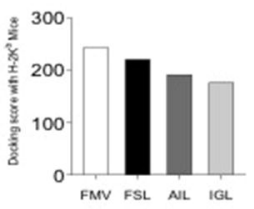

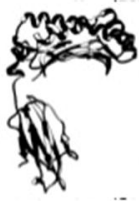

CLAHC (Dark) $\mathrm{H} \cdot 2 \mathrm{~K}^{\mathrm{b}} \mathrm{HC}$ (light)

Superposition (RMSD 1.5A)

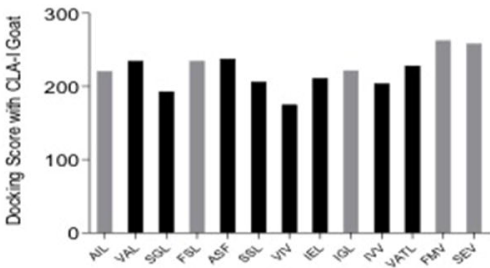

Predicted PPRV peptides

F

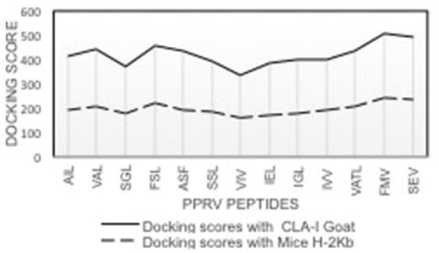


Figure 8

A

B

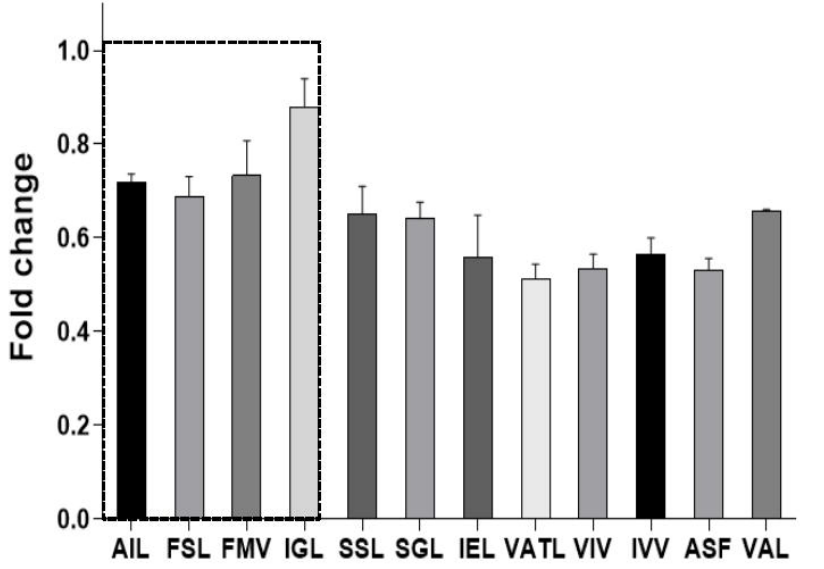

AIL

FMV

IGL

FSL
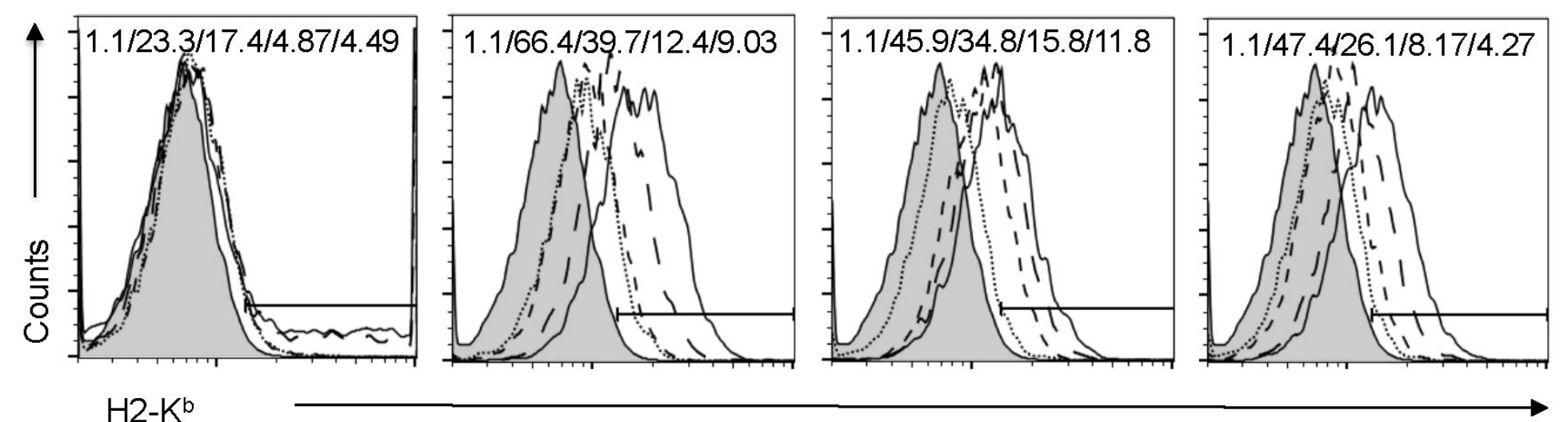

$\mathrm{H} 2-\mathrm{K}^{\mathrm{b}}$

C

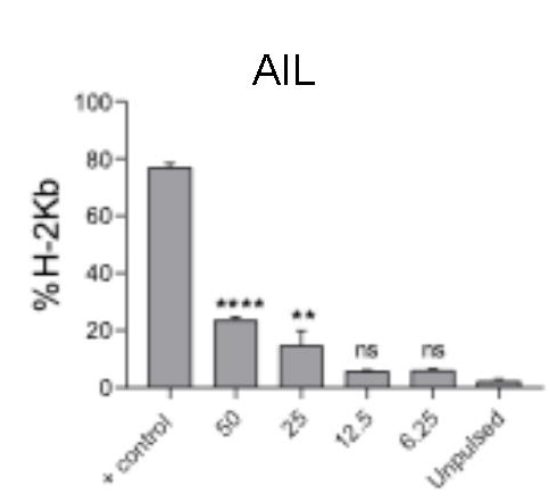

Conc $(\mu \mathrm{g} / \mathrm{ml})$

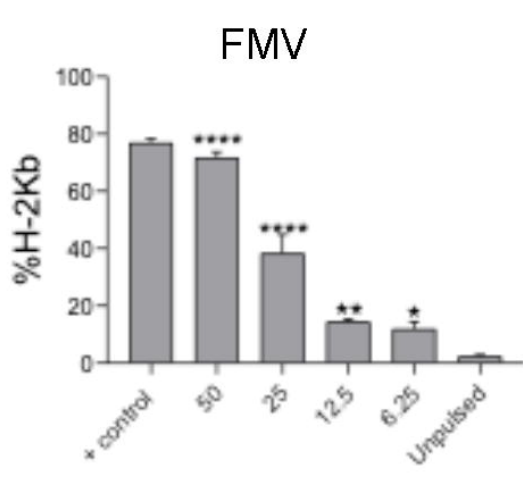

Conc $(\mu \mathrm{g} / \mathrm{ml})$

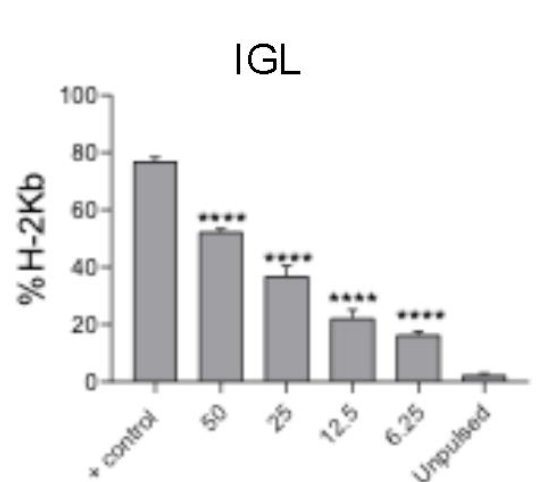

Conc $(\mu \mathrm{g} / \mathrm{ml})$

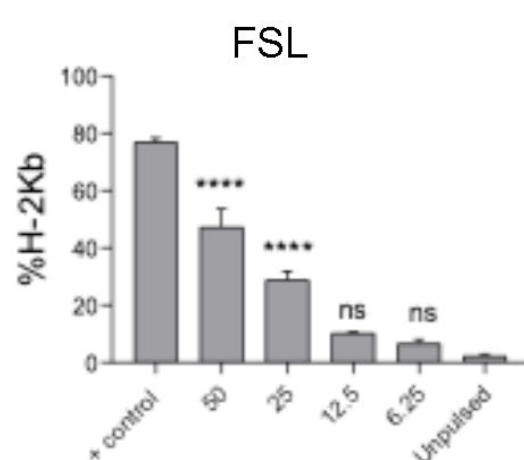

Conc $(\mu \mathrm{g} / \mathrm{ml})$

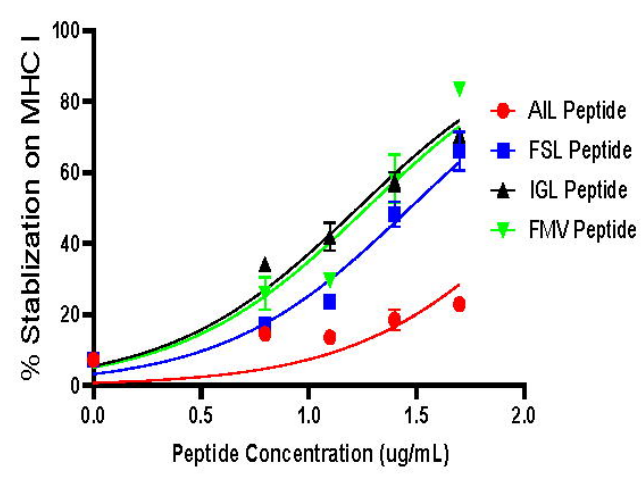

Peptide Concentration (ug/mL) 
Figure 9

A

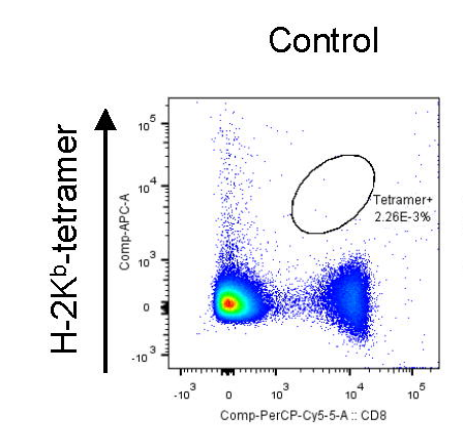

CD8

D

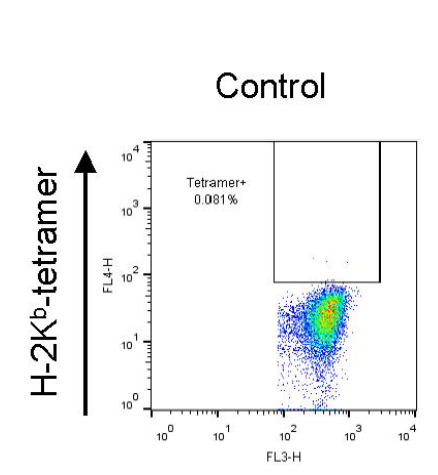

CD8

\section{+ PPRV}

FMV
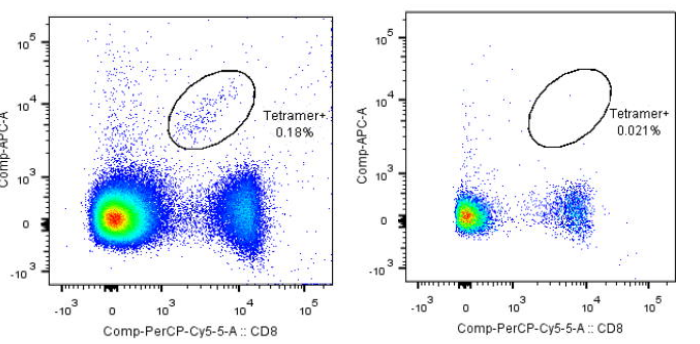

B

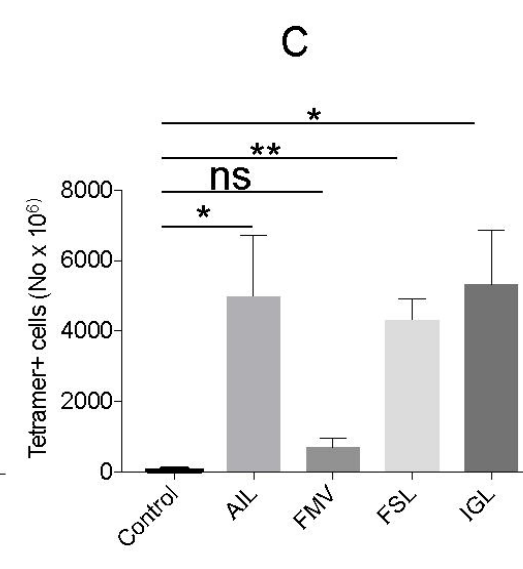

E

+ Peptide

FMV

FSL

IGL

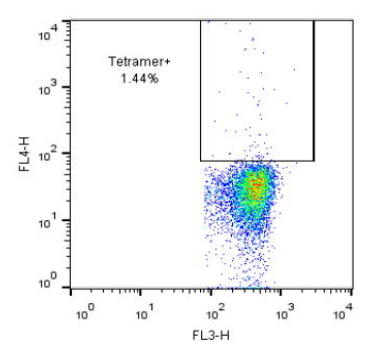

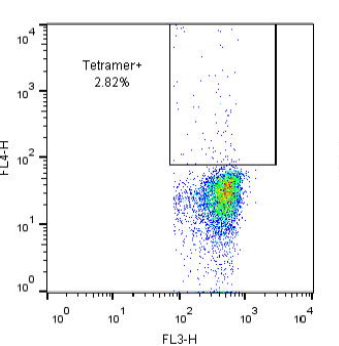
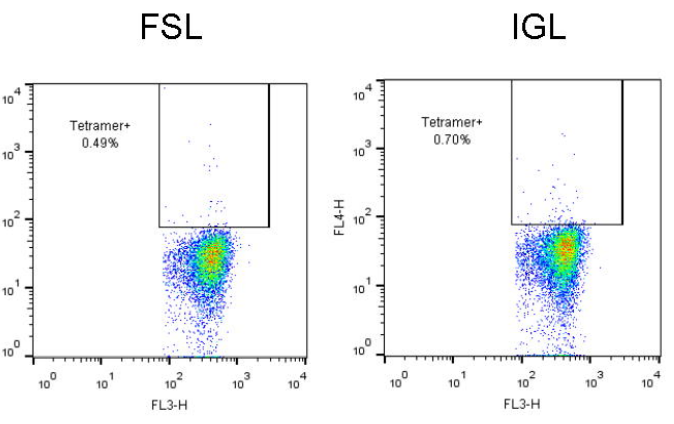

$\underbrace{10^{2}}_{102}$

- Immunized

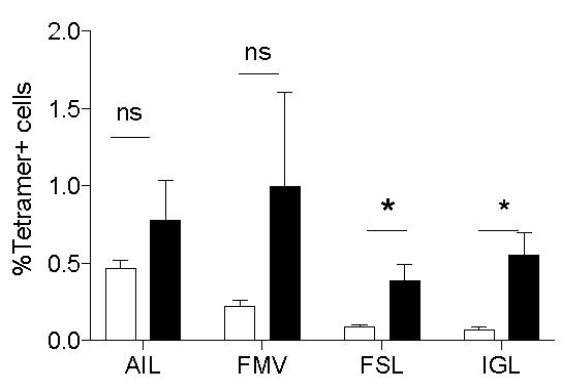

IGL

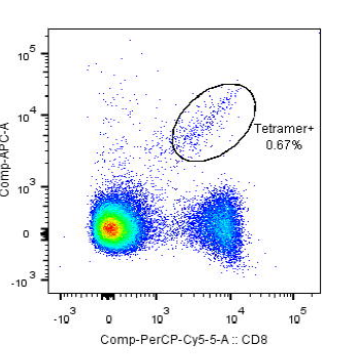

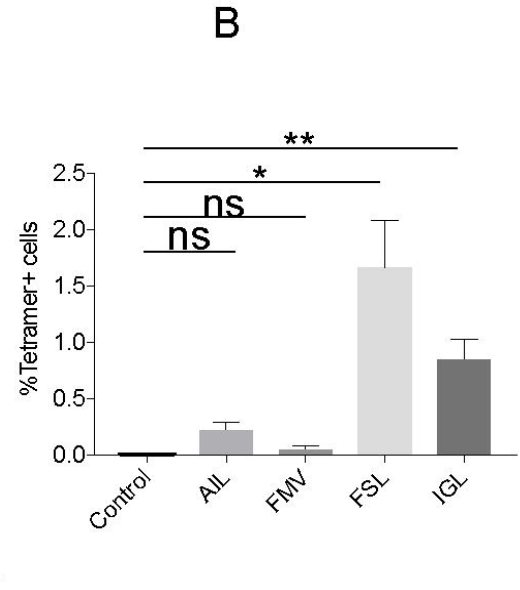

$\square$ Unimmunized 